\title{
Research
}

\section{Landscape Patterns of Exurban Growth in the USA from 1980 to 2020}

\author{
David M. Theobald ${ }^{1}$
}

\begin{abstract}
In the United States, citizens, policy makers, and natural resource managers alike have become concerned about urban sprawl, both locally and nationally. Most assessments of sprawl, or undesired growth patterns, have focused on quantifying land-use changes in urban and metropolitan areas. It is critical for ecologists to examine and improve understanding of land-use changes beyond the urban fringe-also called exurban sprawl-because of the extensive and widespread changes that are occurring, and which often are located adjacent to or nearby "protected" lands.

The primary goal of this paper is to describe the development of a nationwide, fine-grained database of historical, current, and forecasted housing density, which enables these changes to be quantified as a foundation for inference of possible ecological effects. Forecasted patterns were generated by the Spatially Explicit Regional Growth Model, which relates historical growth patterns with accessibility to urban and protected lands. Secondary goals are to report briefly on the status and trend of exurban land-use changes across the U.S., and to introduce a landscape sprawl metric that captures patterns of land-use change. In 2000, there were $125729 \mathrm{~km}^{2}$ in urban and suburban $(<0.68$ ha per unit) residential housing density nationwide (coterminous USA), but there were slightly over seven times that $\left(917090 \mathrm{~km}^{2}\right)$ in exurban housing density (0.68-16.18 ha per unit). The developed footprint has grown from $10.1 \%$ to $13.3 \%$ (1980 to 2000), roughly at a rate of $1.60 \%$ per year. This rate of land development outpaced the population growth rate $(1.18 \%$ per year) by $25 \%$. Based on model forecasts, urban and suburban housing densities will expand to $2.2 \%$ by 2020 , whereas exurban development will expand to $14.3 \%$.
\end{abstract}

Key Words: cross-scale edge; exurban sprawl; forecast model; landscape sprawl metric; land-use change; resilience

\section{INTRODUCTION}

Urban sprawl-or undesirable land-use patternsand its general effects have been discussed by a variety of researchers, decision makers, and concerned interest groups (Alig and Healy 1987, Ewing 1994, Bank of America 1996, Sierra Club 1998, Benfield et al. 1999, Katz and Liu 2000, Waldie 2000, Ewing et al. 2005). A recent special feature of Ecology and Society directly addressed the interface of urban sprawl and ecology, and its primary outcome was the conclusion that, central to the integration of ecology and society, is better understanding of the consequences of land-use changes on natural resources and ecological processes (Ricketts and Imhoff 2003).
Research is needed to improve understanding of the patterns, rates, and ecological effects of urban sprawl, but another type of land-use change is occurring that has important ecological implications as well. Here, I argue that it is critical for ecologists to examine and improve understanding of land-use changes beyond the urban fringe-also called "exurban sprawl" or rural residential development -because of the extensive and widespread changes that are occurring, and because they often are located adjacent to or nearby "protected" lands meant to conserve natural resources and biodiversity. Daniels (1999) defines rural sprawl as low-density residential development scattered outside of suburbs and cities, and as commercial 
strip development along roads outside cites. Nationwide, exurban land use occupies five to ten times more area than urban and suburban densities, and has been growing at a rate of about $10-15 \%$ per year (Theobald 2000, Theobald 2001a), which exceeds the rate of urban development (Natural Resources Conservation Service (NRCS) 2001).

Many researchers have examined land-use change and sprawl, but they typically focus on urban systems. One frequently used quantitative definition of urban sprawl is a decline in population density over time (El Nasser and Overberg 2001, Firestone 2001). For example, Rusk (1997) found that, for 213 urbanized areas, the population grew by $47 \%$ between 1960 and 1990, whereas urbanized land increased by $107 \%$. Thus, the general notion of urban sprawl is that the spatial spread of development proceeds at a greater rate than population growth, resulting in dispersed, lowdensity development.

Most urban sprawl studies have used Census Bureau-defined Urban Areas (UAs) and Metropolitan Statistical Areas (MSAs) (e.g., Pendall 1999, Kolankiewicz and Beck 2001, Lang 2003, Ewing et al. 2005), which can both over- and under-bound locations of urban density (Theobald 2001a). That is, most small cities and towns in the U.S. (census places) were not located within an UA or MSA, and so many towns and cities of generally less than 50 000 residents were excluded from these analyses. Urban density is defined by the U.S. Census Bureau as greater than 1000 people per square mile (about 3.9 people per ha; 1.6 people per acre), whereas rural areas are simply defined as "not urban." Note that "smart growth" density (i.e., the density that would support mass transit) is much higher at 12500 people per square mile (about $>48$ people per ha; $>19.5$ people per acre). Also, because MSAs are defined by amalgamations of counties, rural areas containing very low population densities within a county are often mixed with highly urbanized areas in these analyses.

Some researchers have recognized sprawl as a multidimensional phenomenon rather than simply a decline in the average population density over time (e.g., Torrens and Alberti 2000, Ewing et al. 2002). For example, Ewing (1997) argued that sprawl is characterized by leapfrog,scattered, strip, lowdensity, or single-use forms of development. Alberti (1999) identified four structural variables: form, density, grain, and connectivity. A useful conceptual definition of sprawl comes from Galster et al. (2000, page 5): "Sprawl (n.) is a pattern of land use in a [urban area] that exhibits low levels of some combination of eight distinct dimensions: density, continuity, concentration, compactness, centrality, nuclearity, diversity, and proximity." In a comprehensive examination of urban growth, Ewing et al. (2002) characterized sprawl by computing indicators of residential density, mix of services, activity centers, and accessibility of the street network. Most recently, work on urban morphology continues to emphasize multiple characteristics of growth (Song and Knaap 2004). Although progress is being made on characterizing urban sprawl, less work has investigated land-use change in exurban and rural areas.

The lack of geographic precision exhibited in most urban sprawl studies is one of the main reasons that a rethinking of the urban-rural framework has been called for (Alonso 1993, page 26): "The existing censal categories are misleading because they present a vision of the United States as a territory tiled with convex, continuous, mutually exclusive types of regions, while the reality is one of a great deal of interpenetration, much of it rather finegrained." Revisions to the 2000 Census have partially addressed this issue through "urban clusters," which contain between 500-1000 people per mile ${ }^{2}$ in blocks adjacent to UAs. Moreover, it is common to measure and express the pattern and extent of development through population or population density. However, because population data from the Census Bureau are tied to the primary place of residence, measures based on population underestimate landscape change because housing units in the form of vacation and second homes are not represented. Therefore, housing density is a more complete and consistent measure of landscape change than population density.

The main difficulties to knowing about exurban land-use changes stem from three related factors. Exurban land-use activities tend to be less intensive than urban land uses, and as a result, are more difficult to define and map (Ward et al. 2000). Typically, spatially explicit efforts to examine spatial patterns of exurban dynamics have been limited to case study assessments (e.g., Theobald et al. 1996, Wilson et al. 2004, Robinson et al. 2005). Although there are a number of federal (and state) efforts to inventory natural resources such as the U. S. Census of Agriculture, Population, and Housing, and the NRCS's National Resource Inventory 
(NRI), these tend to provide county-level summaries that are insufficient for ecological inference because important exurban land-use patterns cannot be spatially resolved. The U.S. Geological Survey's National Land Cover data set (NLCD) (Vogelmann et al. 2001) provides fine resolution $(30 \mathrm{~m})$ data, but like the other commonly available inventories, is based on coarse categories that do not differentiate important land-use types beyond the urban fringe (e.g., urban vs. rural).

I emphasize here that ecological assessments of development patterns need to be based on data sets that allow fine-grained differentiation of land-use patterns across the urban to exurban to rural spectrum. Moreover, because a primary conservation response to perceived sprawl is to establish protected lands and open space through direct purchase and conservation easements on privately owned lands, then protected lands, in addition to developed lands, need to be resolved in finer detail as well. Many efforts to estimate sprawl based on undifferentiated geographies, such as UAs or MSAs, may, ironically, have overestimated sprawl because protected areas (with no or very low population) within an urban area were not resolved, yet contributed to the density calculations. For example, the population density of Fort Collins, Colorado, USA, computed using the city boundary, declined from 4.05 to 3.72 people per acre from 1980 to 1998 , suggesting that it "sprawled." But, after removing protected lands within city limits (purchased in large part to counteract sprawl), population density increased from 4.05 to 4.27 in 1998 (Theobald 2004). Although the amount of developed area expanded, Fort Collins grew in a more efficient manner (as measured by population density), after adjusting for fine-grained land-use pattern, and incorporating protected lands.

My work presented here builds on the premise that to advance understanding of the ecological effects of urbanization and human population growth requires recognition of land-use dynamics beyond the urban fringe, and spatial databases of development and protected lands that contain finegrained, spatially explicit data. Because ecosystems do not follow political boundaries, a consistent, comprehensive, and seamless data set of regional to nationwide land use is needed to fully support geographical analyses and assessments of ecological effects of land-use change. The overall objective in this paper is to broaden discourse about better understanding of land-use dynamics and ecological effects to include changes beyond the urban fringe. My primary goal is to describe the development of a nationwide, fine-grained database of historical, current, and forecasted housing density. Secondary goals are to briefly report on the status and trend of exurban land-use changes across the U.S., and to introduce a landscape sprawl measure that captures patterns of land-use change - especially the spatial configuration between protected and exurban areas.

\section{METHODS}

This research was conducted in five general steps. First, I estimated historical and current housing densities at a fine grain to examine spatial patterns of development across the coterminous U.S. Decadal sequences of housing density from 1940 to 2000 were constructed. Using historical and current housing density patterns as data inputs, I developed a simulation model to forecast future housing density patterns based on county-level population projections. I evaluated the forecast model by "hindcasting"-i.e., generating a test data set with model runs that started from estimated 1980 patterns and generated forecasted patterns for 1990 and 2000. The results from the hindcasts were then compared with the estimated ("truth") patterns in 1990 and 2000. I chose to concentrate on recent and near-term patterns from 1980 to 2020 because most conservation planning issues involve roughly 20 year horizons, and these data are the most reliable as well. Next, I developed a metric that measures the spatial pattern and configuration of housing density to better quantify "sprawl" and landscape fragmentation.

Based on the Census Bureau's definition of urban areas, I define "urban" housing densities as less than 0.1 ha per unit, and "suburban" as $0.1-0.68$ ha per unit. I define "exurban" density as $0.68-16.18$ ha per unit to capture residential land use beyond the urban-suburban fringe comprising parcels or lots that are generally too small to be considered productive agricultural land use (although some high-value crops, such as orchards, are a notable exception). "Rural" is defined as greater than 16.18 ha per unit, where the majority of housing units support agricultural production. In some states, where farming can be productive even for small acreage farms ( 8-10 ha), exurban areas could be defined as having between $0.68-8.09$ ha per unit. 


\section{Estimating Historical and Current Housing Density}

To estimate historical and current housing density patterns, I created maps of housing density using dasymetric mapping techniques (Wright 1936, Robinson et al. 1995). I used the best available, finegrained and national-extent spatial database on population and housing from the Census Bureau's block-group and block data for 2000 (U.S. Census Bureau 2001a). Below, I describe census geography basics and a few refinements to common dasymetric techniques that have been detailed in previous work (Theobald 2001a, 2003).

Using census geography, the familiar census tract was subdivided into a block-group (containing roughly 250 to 550 housing units). Block-groups were in turn subdivided into blocks that are roughly a block or so in size in urban areas, but may be many square kilometers in rural areas. These block-groups and blocks tessellate or cover the entire U.S. (U.S. Census Bureau 2001a). Nationwide in 2000, there were 207469 block-groups and 8185004 blocks. The boundaries of census blocks typically follow visible physical features, such as streets, roads, streams, railroad tracks, and ridgelines, and occasionally are based on invisible features, such as city or county limits, property lines, or short extensions of streets (U.S. Census 2001a). Blocks vary in shape and size, ranging roughly from 1-2 ha in urban areas to 100-1000 ha in rural areas.

Because houses are not allowed on public and protected lands, I removed the portions of blocks that overlapped with protected lands identified in the Protected Areas Database (DellaSala et al. 2001), which is the best available, nationwide data set, and provides data mapped at a scale of roughly 1:100 000 on public lands. Most privately owned protected lands (e.g., through conservation easements) and local government lands (i.e., cities and counties), however, were not included in this database, but are a high priority need for future work. In addition, housing units were precluded from occurring in so-called "water blocks," which represent hydrological features, such as streams, rivers, ponds, lakes, and reservoirs. As an example, Colorado contains about 141000 blocks, 75000 of which contain at least one housing unit (mean = 262.1 ha; SD = 1652.0 ha). Removing the portion of blocks that overlap protected areas refines them considerably $($ mean $=163.04$ ha; $S D=833.9$ ha $)$. Using refined blocks results in over 131600 additional hectares $(\sim 18 \%)$ being defined as exurban along the wildland interface in western Colorado.

Although the refined blocks result in a finer-grained data set, an assumption must be made about the spatial distribution of units within a refined block. Typically, dasymetric mapping techniques assume a homogenous distribution (e.g., Theobald 2000; Eicher and Brewer 2001; Theobald 2001b; Theobald 2003). Another option is to constrain the distribution of units based on land cover types (e.g., Monmonier and Schnell 1984; Holloway et al. 1999; Schumacher et al. 2000; Radeloff et al. 2001), but Eicher and Brewer (2001) found no significant improvement in distribution when land use/cover was incorporated.

I modified the spatial distribution of housing units within a block based on the density of major roads, because houses were more likely to be located near roads and less likely to be in portions of blocks that are distant $(>\sim 1 \mathrm{~km}$ ) from roads (Theobald 2003). The allocation of housing units were weighted based on road density $\left(\mathrm{km} / \mathrm{km}^{2}\right)$ computed using a moving neighborhood with an $800-\mathrm{m}$ radius, which is arbitrary but is supported by a moderately strong correlation between housing and road density (Theobald 2003). Density was computed using a commonly available, nationwide data set of major roads generated from the U.S. Census TIGER data set (2004 data and maps from Environmental Systems Research Institute (ESRI), Redlands, California, USA). Road density was classified into four categories to distinguish different levels of development based on an ad hoc comparison of road densities and housing densities around the nation. The classes used were: very low $\left(0.0-0.25 \mathrm{~km} / \mathrm{km}^{2}\right)$, low $\left(0.25-1.0 \mathrm{~km} / \mathrm{km}^{2}\right)$, medium $\left(1.0-5.0 \mathrm{~km} / \mathrm{km}^{2}\right)$, and high $\left(>5.0 \mathrm{~km} / \mathrm{km}^{2}\right)$. Weights of $1,2,3$, and 4 were assigned to very low to high (respectively), and were used to allocate housing density values to cells within a block.

The number of housing units per block was obtained from the $100 \%$ sample data from the 2000 Census Summary Tape File 1 (U.S. Census Bureau 2001b). Historical patterns of housing density (decadal from 1940 to 1990) were generated from estimates obtained from the "Year Housing Built" question from the sample data Summary File 3 data set (U. S. Census Bureau 2001c). Because the geography of tracts and blocks changes with each census, I estimated historical housing units based on the 2000 
Census geography using established methods (Radeloff et al. 2001, Theobald 2001a, Hammer et al. 2004). Housing unit counts for each decade are provided at the block-group level and were adjusted to ensure that the sum of units by block-groups in a county equaled the counts from decadal census. This minimizes systematic underestimation of historical units.

Estimates of exurban housing density computed from these data are conservative because units are assumed to be distributed roughly evenly throughout a block. Therefore, estimated housing density will tend to be lower because higher density areas within a block are "averaged out." Note that the variable-sized analytical units cause possible inaccuracies, which is widely recognized as the modifiable areal unit problem (Openshaw 1984). Analyses based on Census data are subject to these limitations, but to date, there is no easy, practical solution to these difficulties (Longley et al. 2001). It is important to note that the resolution or "grain" of the refined blocks, represented at $100 \mathrm{~m}$ resolution, is coarser than land cover information from U.S. Geological Survey's NLCD (30 m), but because the boundaries of blocks are often based on visible physical boundaries, their shapes often conform to important features on the landscape that control the distribution of houses.

\section{Forecasting Future Housing Density}

Most efforts to forecast land-use change have focused on urban systems (e.g., Landis 1995, Batty 1997, Clarke 1997, Wilson et al. 2003, but see Theobald and Hobbs 1998). In previous work, I created a model to forecast future patterns of housing density across the urban-to-rural gradient, named the Western Futures model (Theobald 2001b, Theobald 2003, Claggett et al. 2004). Here, I describe additional refinements that have resulted in a new model called SERGoM v1 (Spatially Explicit Regional Growth Model). The full urbanto-rural spectrum of housing densities is modeled in SERGoM at broad regional-to-national extents. It uses a supply-demand-allocation approach, and assumes that future growth patterns will be similar to those found in the past decade, although this can be parameterized to reflect alternative scenarios.

There are three basic steps in SERGoM to forecast future patterns on a decadal basis (Fig. 1). First, the number of new housing units in the next decade is forced to meet the demands of the projected countylevel population. There is significant variability in the population per housing unit ratio (area-weighted mean $=2.509, \mathrm{SD}=2.383$ ), so that in the 2000 Census, 440 counties had $<2.0$ people/unit and 70 counties $<1.5$ people/unit. Rather than using a single nationwide conversion factor, population growth was converted to new housing units by the countyspecific housing unit per population ratio for 2000 . Population estimates were obtained from a demographic-econometric model (NPA Data Services 2003).

The second step was to compute a location-specific average growth rate from the previous to current time step (e.g., 1990 to 2000). These growth rates were computed for each $100-\mathrm{m}$ cell using a moving neighborhood $($ radius $=1.6 \mathrm{~km})$. For each state, I computed the average growth rate for each of 16 development classes. These 16 classes were found by overlaying four density classes (urban, suburban, exurban, and rural) with four accessibility classes measured as travel time (minutes one way) from the nearest urban core (see below): 0-10, 10-30, 30 60 , and $>60$ minutes. Growth rates averaged over the classes generated from the housing density and accessibility patterns that reflect the previous time step were then joined to a map that depicts the current time step housing density and accessibility pattern. Because these classes and rates are computed locally, both within-county heterogeneity and cross-boundary patterns can be captured. This allows rates of growth to vary across the nation, across a region, and even within a county, and does not assume stationarity.

The distribution of new housing units was adjusted according to accessibility to the nearest urban core. That is, growth typically occurs at locations on the urban fringe. Accessibility from all developable land to the nearest urban core was computed-based not simply on straight-line distance, but in terms of minutes of travel time from a location along the main transportation network (major roads and highways) to the nearest urban core. An urban core area is defined here as a contiguous cluster (>100 ha) at urban housing density, but alternative definitions could be developed. Because it is difficult to forecast when roads will be enlarged or where new roads will be constructed, travel time to move across locations that are not on the network of major roads was modeled as an average travel time of 15 miles per hour (24.2 km/hour). Travel speed was assumed 
Fig. 1. A basic logic diagram of the Spatially Explicit Regional Growth Model (SERGoM v1).

\section{SERGoM v1}

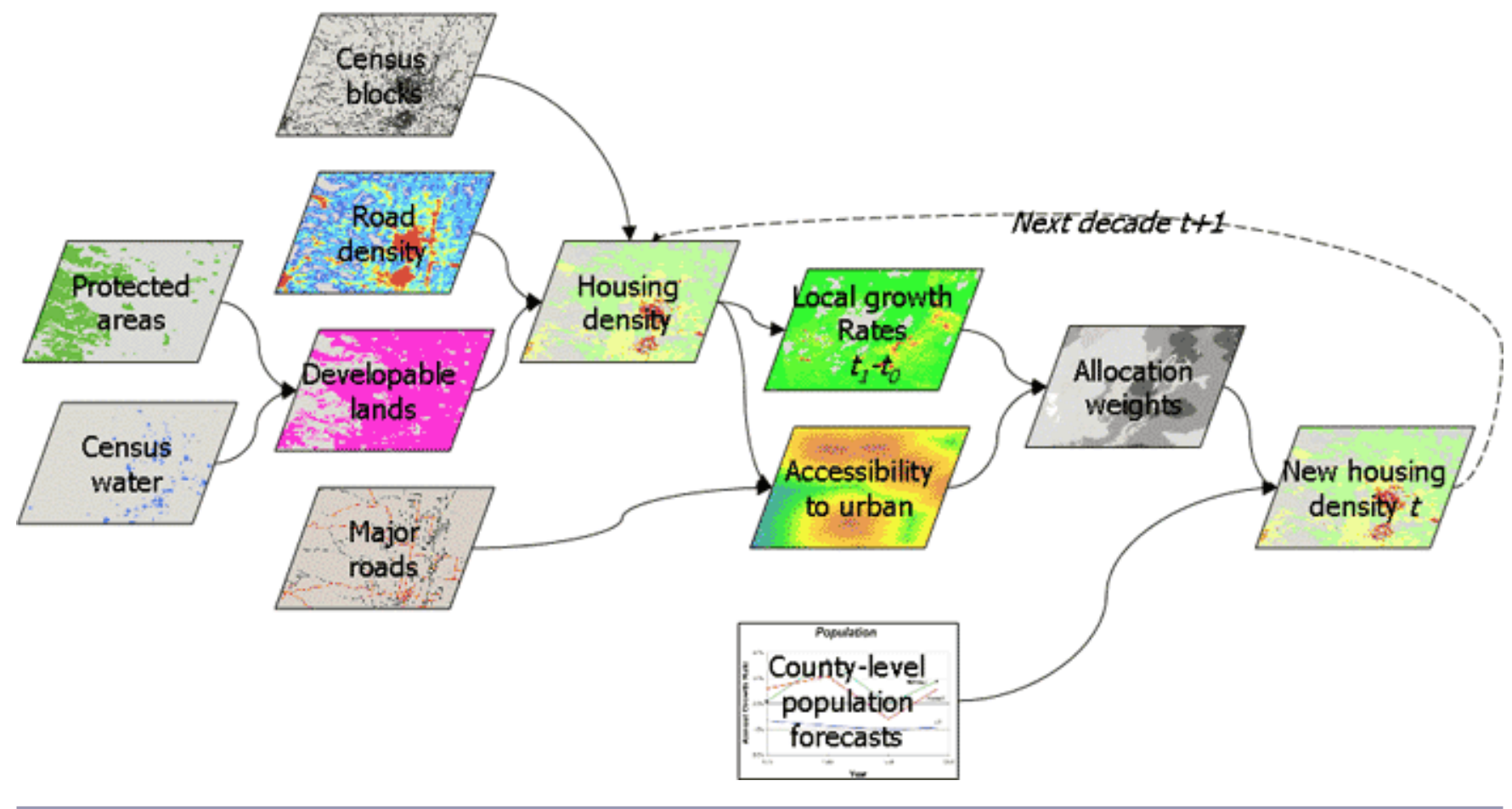

to be $70 \mathrm{mph}(113 \mathrm{~km} /$ hour $)$ on interstates, $55 \mathrm{mph}$ (89 km/hour) on highways, and $45 \mathrm{mph}(72.4 \mathrm{~km} /$ hour) on major county roads. An accessibility surface was then created from a cost weight based on travel time from urban areas along major roads. New housing units are allocated as a function of the accessibility surface. Here, the allocation is based on the distribution of new units realized in the previous decade, but other weightings could be applied to develop denser or more dispersed growth scenarios. Accessibility is computed at each decadal time step because new "islands" of urban core may emerge over time. This allows complex growth patterns to be modeled, and incorporates the emergent nature of development patterns.

The third step was to add the map layer of new housing density to the current housing density (e.g., adding new housing units to 2000 housing density). SERGoM assumes that housing density cannot decline over time. This is a reasonable assumption when examining patterns of expansion in suburban and exurban areas. However, this current implementation is limited when investigating urban-centric processes, such as urban decay or expansion of commercial land use into urban and suburban residential areas. Future development of SERGoM could include commercial and industrial land cover data (e.g., from the U.S. Geological Survey's NLCD) to incorporate commercial/ industrial and residential dynamics in urban areas.

\section{Evaluation of Forecast Model}

To evaluate forecasts of urban, exurban, and rural housing density patterns generated by SERGoM, I ran the model with the 1980 estimated housing density pattern as the initial conditions (in place of 2000), and then generated forecasts for 1990 and 2000. I then compared the estimated development patterns to forecasted patterns for 1990 and 2000 data sets. A simple way to examine the accuracy of the forecasted patterns is to generate a "confusion 
matrix" or cross-tabulation of the area of intersection of the nine possible combinations (of three classes). To examine how accuracy changes with coarser-resolution representations of the data, I followed a multi-resolution approach (Costanza 1989, Pontius 2002) where I averaged the housing density maps from their original resolution of 1 ha to coarser resolutions of $4,16,64$, and 256 ha. At each resolution, I re-computed the housing density classes (urban/suburban, exurban, and rural) and recomputed a cross-table for each combination of year and resolution.

\section{Landscape Measures of Development Patterns}

Most research effort has measured the pattern of land use, but less work has quantified how land-use change modifies or affects habitat and natural resources. Pattern is defined here as the structural arrangement of different land-use types, which are defined based on housing density. Few researchers have explored the usefulness of common landscape ecology metrics (e.g., Torrens and Alberti 2000). For example, Luck and Wu (2002) used FRAGSTATS (McGarigal and Marks 1995) and found several metrics useful to differentiate the urbanization gradient. Patch-based landscape metrics have also been used to examine patterns of sprawl (Carrion-Flores and Irwin 2004, Hasse and Lathrop 2003, Robinson et al. 2005). However, a primary criterion to judge the usefulness of a metric is establishing a clear link between the landscape metric and the land-use process.

Here, I introduce a metric to quantify the effects of exurban and rural development on natural resources, from a landscape perspective. The landscape sprawl metric, $L S$, quantifies three primary aspects of residential development patterns (Fig. 2): density, continuity, and configuration (the latter roughly incorporates concentration, compactness, centrality, nuclearity, accessibility, and proximity). More work needs to be done to examine the sensitivity of this metric to different regional situations and land-use processes.

Commonly the analytical unit or area (the denominator in density calculations) is typically defined by city limits, urbanized areas, or metropolitan statistical areas, but computing the density locally for each block allows fine-grained mapping of development patterns to be examined across the urban-to-rural gradient. Also note that protected open space, parks, and lakes should be excluded from the area developed during calculations. At each location, housing density, $D$, is computed using the refined blocks. A threshold, $t$, is used to identify and remove blocks that are presumed to be non-residential land use (e.g., agricultural); here, I assume that lower than exurban densities are primarily non-residential land use. Note that it is difficult to map commercial and industrial land use with these data.

Measuring the continuity of residential development patterns can identify leap-frog development and locations adjacent to residential development in the so-called urban "shadow" or "fringe." I computed a continuity or edge weight (Eq. 1), $S_{\mathrm{E}}$ to penalize development locations that contribute to increased edge between developed and undeveloped/ protected land. This is arbitrarily set to the square root of the housing density (maximum of 5.0) so that edges that have higher density adjacent to undeveloped land are weighted higher than edges formed by lower density development. Note that only edges where developed land is adjacent to undeveloped lands, but developable, are considered; development adjacent to large water bodies and commercial/industrial are not considered discontinuous development. Also, density is smoothed by a $600-$ $\mathrm{m}$ radius window to remove small "islands" or narrow strips of housing development to make the identification of edges more robust and less sensitive to possible anomalies.

$$
S_{E}=D^{0.5}, \max =5.0
$$

To account for vehicle miles traveled and the effects of broader spatial scales or configurations of development, I computed the accessibility (Eq. 2), $S_{\mathrm{T}}$, of a location of residential development to the nearest urban core areas, computed in terms of minutes of one-way travel time, $T$, along the major road network. The average person in the U.S. travels roughly 40 miles per day, most of it in a personal vehicle (U.S. Department of Transportation 2003). Development that is more distant from the urban core is assumed to contribute more vehicle miles traveled. Urban core is defined as a contiguous area of at least 25 ha in size, composed of urban density 
Fig. 2. An illustration of the three components of the Landscape Sprawl (LS) metric. The development pattern (upper left) is based on housing density, classified here to four categories: urban $(<0.1$ ha per unit) comprises $4 \%$ of the area, located at the top, followed by suburban $(0.1-0.68$ ha per unit; $12 \%)$, exurban $(0.68-16.18$ ha per unit; $20 \%)$, and rural (>16.18 ha per unit; $44 \%)$. Protected land (e.g., public national forest, park, etc.) has no housing density and makes up 20\%. LS1-Where rural or protected lands are adjacent to urban, suburban, or exurban densities, an edge contrast weight is computed (upper right). Edges formed by higher density housing lead to a higher edge contrast, and disjoint or "leapfrog" development $(>0.5 \mathrm{~km})$ is also penalized by the edge weight. LS2-To get at spatial configuration of development, the distance (square-root transformed) in minutes of travel time along major roads and highways from urban areas is multiplied by housing density to account for the number of trips or vehicle miles traveled (lower right). Within each class, this component increases slightly with increasing distance, but housing density is fairly dominant, so that suburban areas, even though they are closer, account for a greater impact because of the sheer number of housing units. LS3-The inverse of housing density (units per ha) is land consumption (ha per unit). Note that the final LS metric value is the summation of these three components.

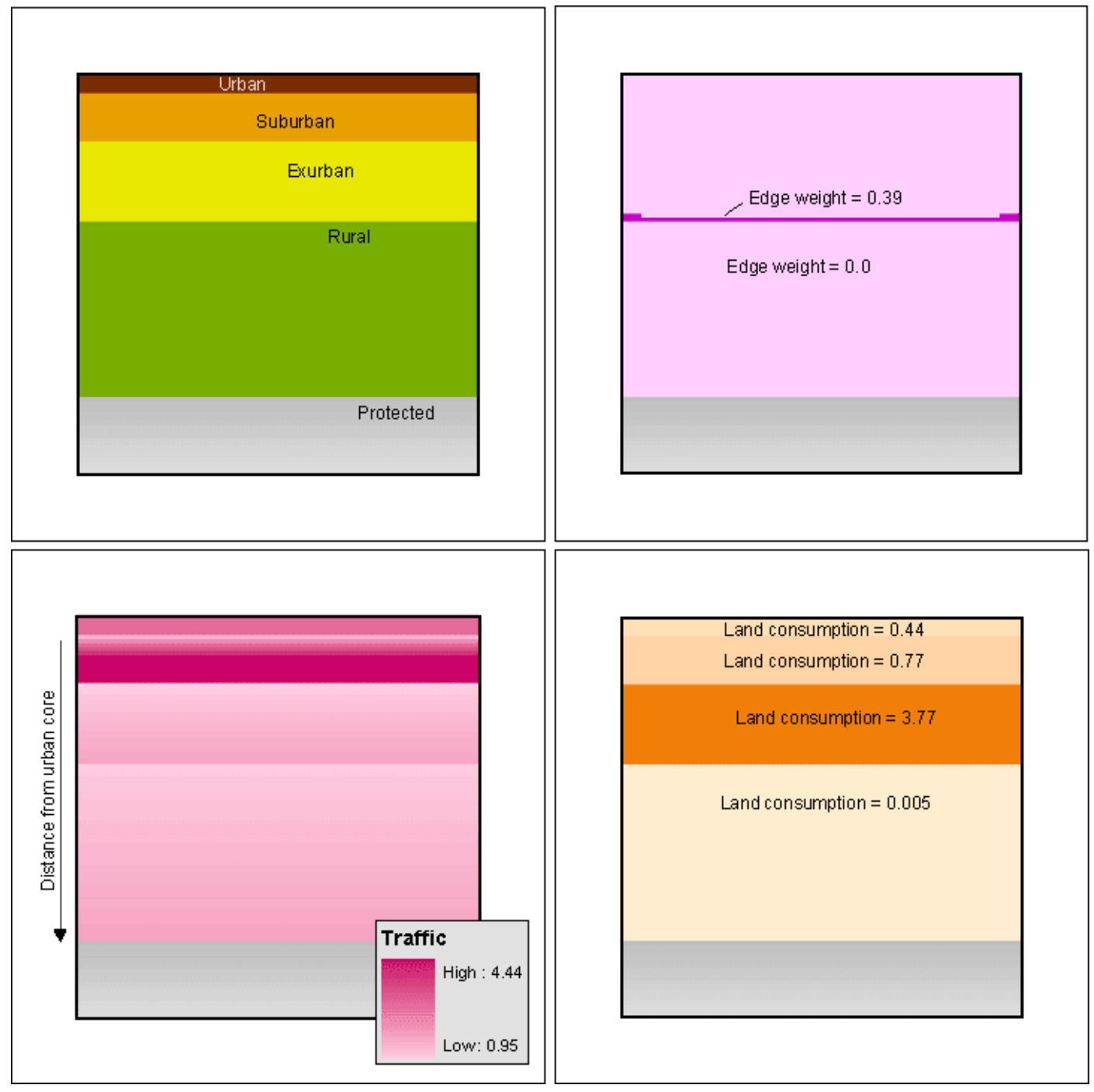


cells. Both the density threshold and minimum area requirements could be changed to create alternative scenarios. Note that accessibility is rescaled using a square-root transform and constrained to be at least 1.0 , so that $T$ increases at a slower rate for longer distances. This transform is performed because, although the majority of vehicle miles traveled occur during long commutes, some portion occurs during errands, which tend to be centralized within urban areas. This transformed time value is then multiplied by the housing density at a location, so that more housing units will result in a higher value, whereas fewer houses will typically generate fewer trips, regardless of the distance from urban areas.

$$
S_{T}=D^{*} T^{0.5}
$$

The last aspect included in the landscape sprawl metric is land consumption, which represents the efficiency with which land is used in situ (Eq. 3). That is, higher density locations are more efficient from a "per person" or "per housing unit" perspective. The inverse of housing density, $1 / D$, is the area of land required per unit $A$. As a result, higher density urban and suburban areas are more efficient in area of land used per unit compared with exurban residential development. Although there is no clear and consistent break point at which agricultural land use no longer becomes viable, there is a rapid threshold that occurs at densities that are often termed hobby ranches or "nonfarm farms." This threshold varies regionally across the U.S., and depends mostly on ecosystem parameters such as soil productivity and precipitation, but also on the structure of ranch/farm operations. Generally, densities that are around 14 ha or more (40-50 acres) are considered part of the productive agricultural system, particularly in the western U.S. (Hart 1992). The area $A$ was square-root transformed to reduce this aspect from dominating this metric. As $A$ exceeds 10 ha, an increasing portion, $u$, of a parcel or lot is useable for agricultural production (or alternatively has higher natural habitat values). For urban, suburban, and exurban densities, $u=1.0$; for rural densities lower than 0.08 units per ha, $u=0.6$; for densities below $0.04, u=0.1$; for densities below $0.03, u=0.001$. These values are estimates, but $u$ could be computed empirically for different regions in the U.S. as the portion of a parcel or lot that does not contribute to agricultural production. For wildlife habitat, $u$ might be an estimate of the proportion of area beyond the "zone of disturbance" associated with housing units (Theobald et al. 1997).

$$
S_{A}=\sqrt{(1 / D) * u}
$$

The final overall landscape sprawl index, $L S$ (Eq. 4), is computed using an equal weighted combination of the three components, which assumes that all components are equally important in the overall metric $L S$ (Fig. 3). Larger values of $L S$ indicate a more sprawling pattern, whereas smaller values denote a more efficient land-use pattern. Locations that have low housing density, that are nearby agricultural lands, and/or that are further from urban core areas will have higher values of $L S$. Locations that have higher density, that do not contribute to discontinuous edges, and/ or that are closer to urban core areas will have lower values of $L S$. Note that the units of $L S$ are expressed roughly in terms of hectares per unit, weighted by accessibility and edge. As a consequence, differences in housing density-between locations, or over time at the same location-have a dominant effect on the landscape sprawl metric. A GIS script (ESRI AML; ESRI, Redlands, California, USA) was used to compute $L S$ (App. 1).

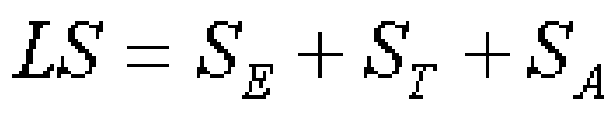

Because $L S$ is measured at each location (cell), it is typically averaged over an area of interest, such as a state, county, or watershed. To illustrate how the $L S$ metric captures different development patterns, I generated a simple hypothetical landscape. Figures 4 and 5 illustrate different development patterns and the value of $\mathrm{LS}$ for each. To calculate trends, $L S$ can be computed on maps that represent different times (Fig. 5). 
Fig. 3. An illustration of how the Landscape Sprawl (LS) metric captures different development patterns. Two additional development configurations that total the same number of housing units (center left, bottom left). The LS is computed for each cell within the $100 \times 100$ landscape, with higher values, represented by a darker hue, indicating more sprawl. With increasing distance from urban core (center), LS increases strongly for suburban density, moderately for exurban density, and weakly for rural areas. Note that the edge contrast weight occurs between the urban/rural and exurban/rural edge, but is clearly visible because of the higher contrast at the urban/rural edge. A general indicator of the overall sprawl score is the mean LS score for a given analytical unit. The mean LS scores increase from top to bottom: 267.8 (top), 338.9 (center), 369.8 (bottom).

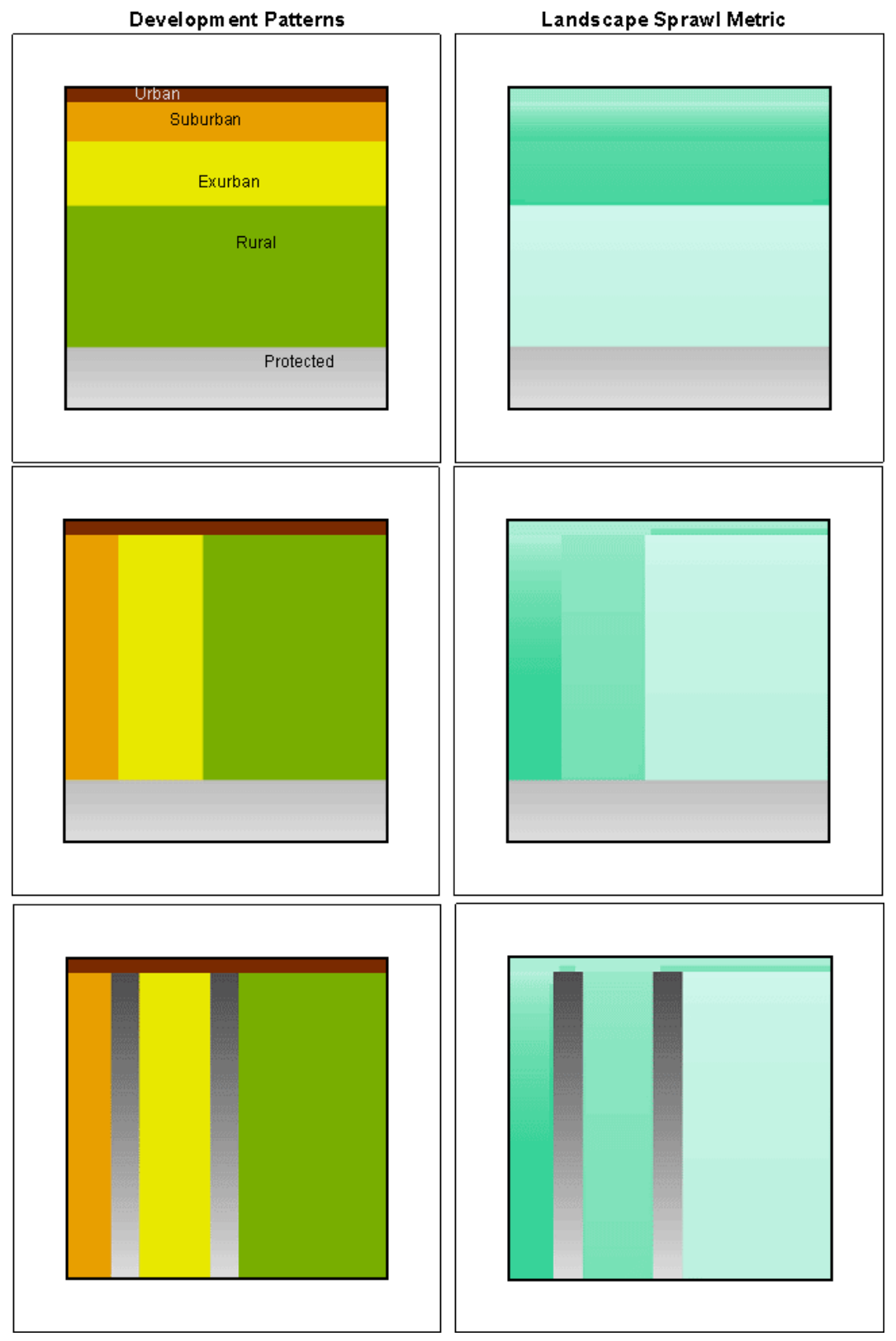


Fig. 4. The landscape metric also captures \&\#8220leapfrog" development and development at further distances - note that the scenarios presented here have the same areal proportions as Fig. 3 (and therefore, the same number of housing units). Compared with a fairly compact pattern (top, and also center Fig. 3), the effect of disjunct development is an increase from 338.9 (top) to 373.9 (center). Moving development yet further afield, the score increases to 399.3 (bottom).
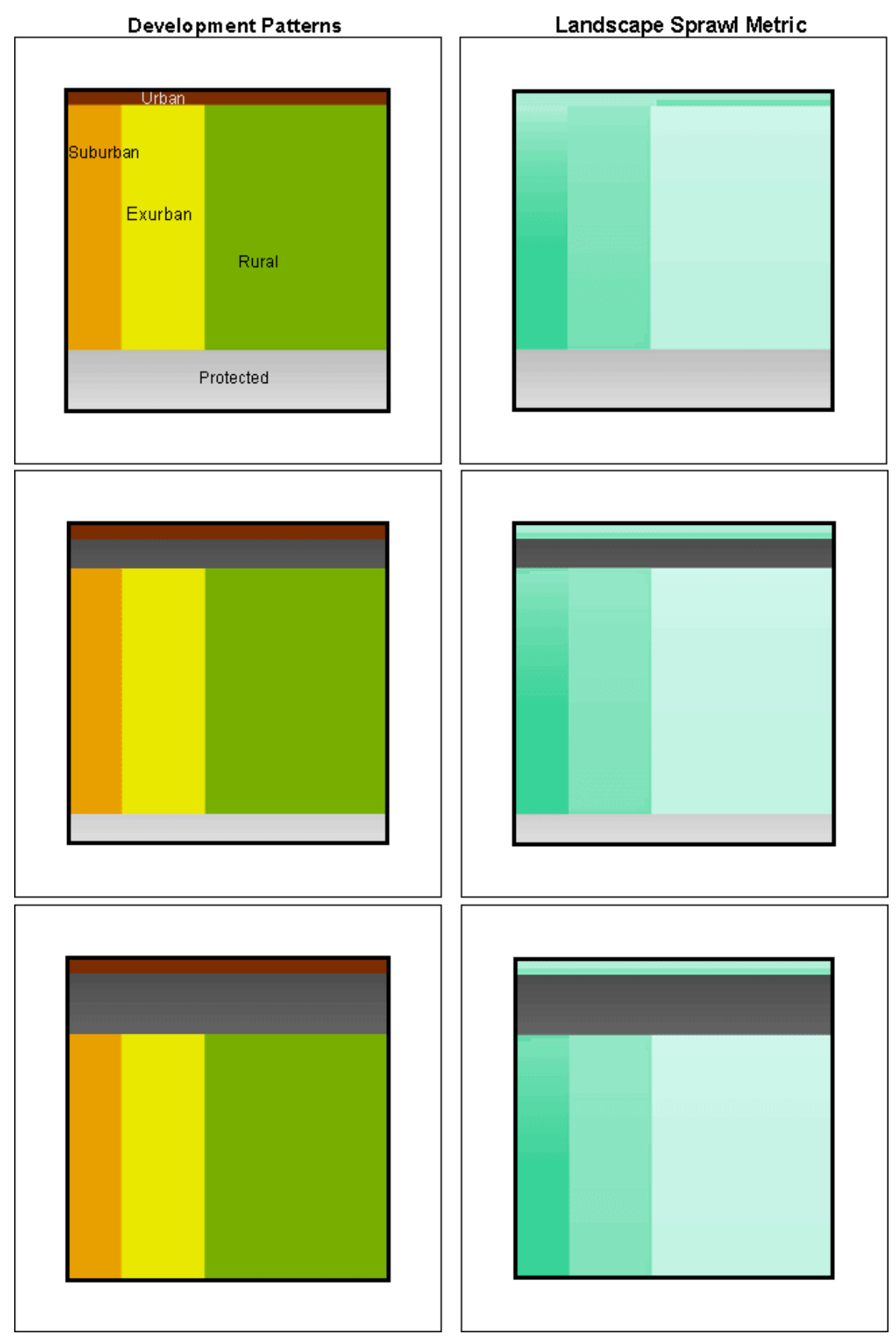
Fig. 5. The Landscape Sprawl (LS) metric also can be used to capture patterns of development over time. The scenarios here reflect a $10 \%$ increase in the original number of housing units (Fig. 3, top). Expanding the area occupied by urban housing density to accommodate the additional housing units increases LS only slightly (274.7, top, compared with 267.8 in the original). The LS metric increases to 286.7 (center) when the suburban class is expanded. LS increases to 403.1 (bottom) when the additional units are developed at exurban densities.

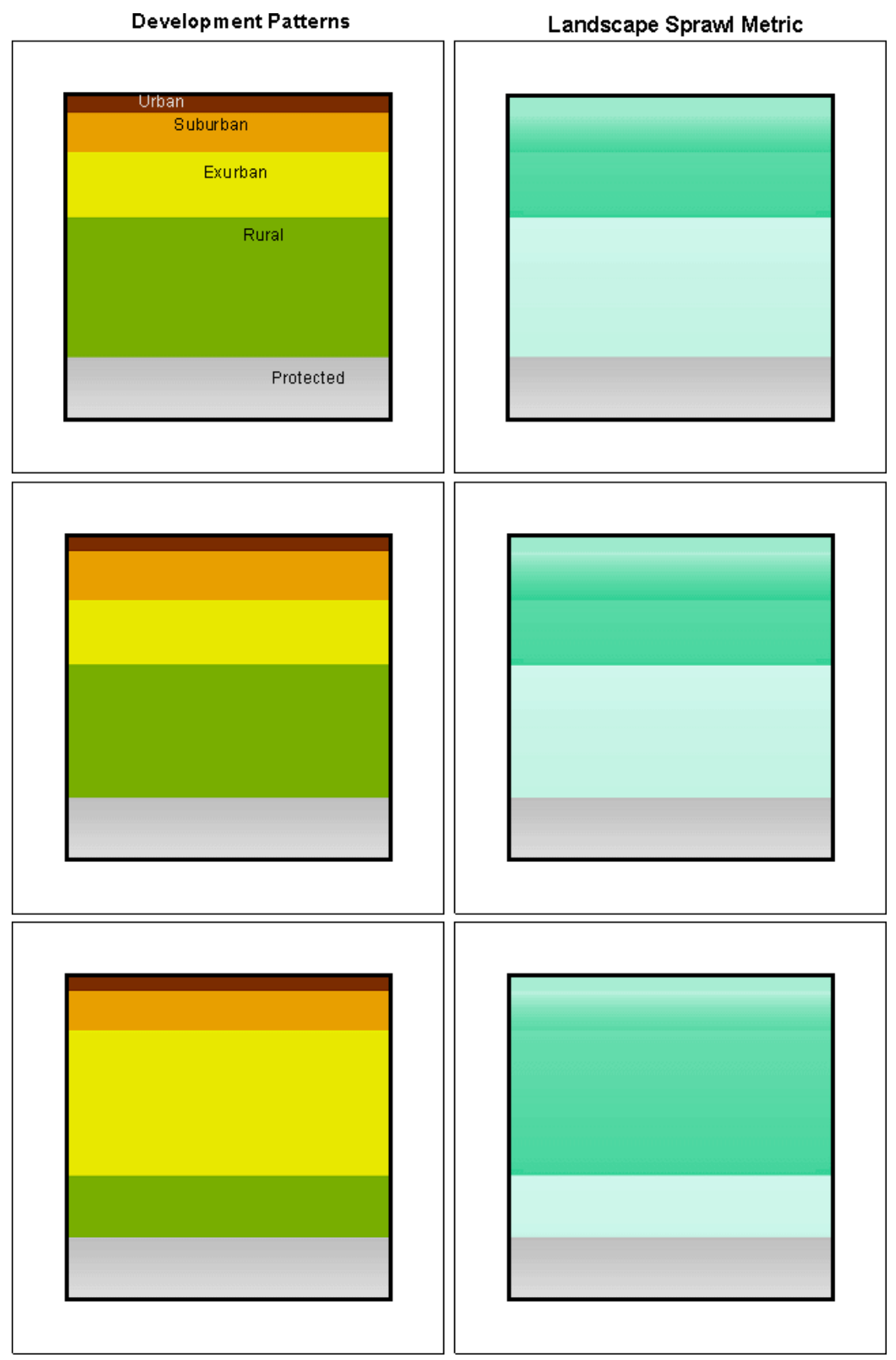


Table 1. The extent of development for the coterminous U.S., grouped by housing density class. "Developable" land includes private lands that do not have some protected designation. "Undevelopable" includes public (e.g., Forest Service, parks, etc.) and other protected lands (derived from DellaSala et al. 2001).

\begin{tabular}{|c|c|c|c|c|c|c|}
\hline \multirow[t]{2}{*}{ Density class } & \multicolumn{3}{|c|}{ Extent $\left(\mathrm{km}^{2}\right)$} & \multicolumn{3}{|c|}{ Percentage of developable land } \\
\hline & 1980 & 2000 & 2020 & 1980 & 2000 & 2020 \\
\hline $\begin{array}{l}\text { Urban/suburban (>0.69 ha/ } \\
\text { unit) }\end{array}$ & 95635 & 125729 & 174226 & $1.7 \%$ & $2.2 \%$ & $3.1 \%$ \\
\hline $\begin{array}{l}\text { Exurban } \\
(0.69-16.18 \text { ha/unit) }\end{array}$ & 693591 & 917090 & 1116046 & $12.2 \%$ & $16.1 \%$ & $19.6 \%$ \\
\hline $\begin{array}{l}\text { Rural } \\
\text { (>16.18 ha/unit) }\end{array}$ & 4891988 & 4638395 & 4275543 & $86.1 \%$ & $81.6 \%$ & $75.2 \%$ \\
\hline
\end{tabular}

\section{RESULTS}

\section{Status and Trends in Developed Lands}

In 2000, there were $125729 \mathrm{~km}^{2}$ in urban/suburban residential housing density nationwide, excluding commercial and industrial lands typically associated with urban areas (Table 1). There are slightly over seven times the additional area in exurban housing density $\left(917090 \mathrm{~km}^{2}\right)$. About $1.6 \%$ of land nationwide (coterminous U.S.) was in urban/suburban residential density, whereas $11.8 \%$ was in exurban in 2000. The urban/suburban/ exurban development footprint has increased from $10.1 \%$ to $13.4 \%$ (1980 to 2000), roughly at a rate of $1.60 \%$ per year. This rate of land development outstrips by $25 \%$ the rate of population growth from the same time period of $1.18 \%$ per year-a conservative estimate because rural lands were not included in the computation, but rural population was included. There were $2107894 \mathrm{~km}^{2}(27 \%)$ in non-developable (i.e., public or private-protected lands). The distribution of these development patterns can be seen in Fig. 6 (low resolution), Fig. 7 (high resolution), and App. 2 (Portable Document File).

To facilitate easy examination of this database, I provide a spreadsheet containing summaries of these data by county (see App. 3). Also, animations of the development patterns from 1980 to 2020 on a decadal basis allow visualization of spatiotemporal patterns for the nation (Fig. 8) and western
(Fig. 9), central (Fig. 10), and eastern U.S. (Fig. 11). Other analytical units, such as hydrologic unit codes (HUC 8-digit codes) or ecoregions, could be used to summarize the housing density data as well.

Another way to examine urban and exurban development patterns is to determine what proportion remains rural: that is, either rural housing density (private lands) or public/protected lands. Ruralness is defined here as the proportion of a county (or state) in rural housing density, or the proportion of the developable area in the county (or state) in rural housing density. The amount developed (urban, suburban, and exurban) is roughly the opposite of the rural landscape (Figs. 12, 13, and 14). Notably, some of the "New West" states (Arizona, Colorado, Idaho, Utah) appear less rural than many of the northern Great Plains states (Iowa, Kansas, Montana, Nevada, North Dakota, South Dakota), because much of the open space is provided by public lands that are "undevelopable."

\section{Model Forecasts}

The SERGoM forecast model performed reasonably well (Table 2), resulting in high accuracy overall for 1990 (urban $=93.0 \%$, exurban $=91.2 \%$, and rural $=99.0 \%$ ) and reasonably high accuracy for 2000 (urban $=84.2 \%$, exurban $=79.4 \%$, and rural $=99.1 \%)$. With coarser resolutions, the accuracy increased minimally for the 1990 pattern and slightly for 2000 (exurban increased from $79.4 \%$ to $82.3 \%$. 
Fig. 6. A low-resolution map showing housing density classes for 2000 .

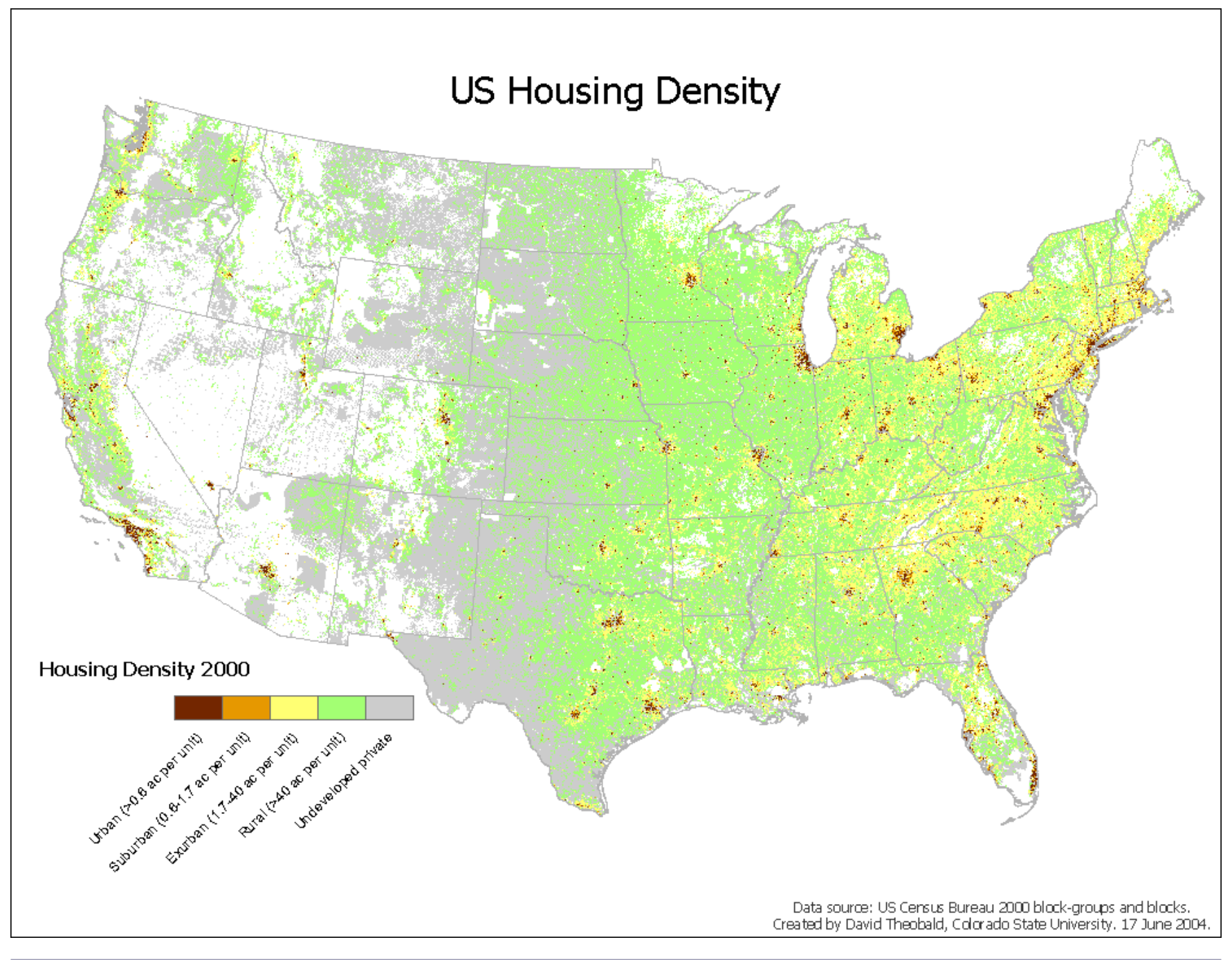

\section{Status and Trends of Landscape Sprawl Metric}

Values of the $L S$ metric ranged from 0.06 to 330.53 throughout the U.S.. $L S$ values increased from 1980 $($ mean $=232.17, \mathrm{SD}=258.40)$ to $2000($ mean $=$ $248.06, \mathrm{SD}=258.55)$ to 2020 (mean $=263.47, \mathrm{SD}$ $=257.11$ ), indicating that exurban development and sprawl have increased throughout the U.S. There is substantial spatial variation of $L S$ between counties, however, and Fig. 15 shows the $L S$ metric averaged by counties for 2000 (and App. 4). Moreover, there is significant local spatial variation within a county (Fig. 16). Surprising spatio-temporal patterns arise in $L S$ because urban core areas may emerge over time, causing a phase change in the $L S$ metric values in a region as municipal goods and services move into new regions (see Fig. 17).

\section{DISCUSSION}

Understanding the patterns and trends of urban sprawl is important, but there are important landuse patterns and dynamics occurring beyond the urban fringe. Not only is the extent of exurban housing density 7-10 times that of urban areas, but per capita land consumption in exurban areas is much greater than in urban locations. 
Fig. 7. A high-resolution map showing housing density classes for 2000.

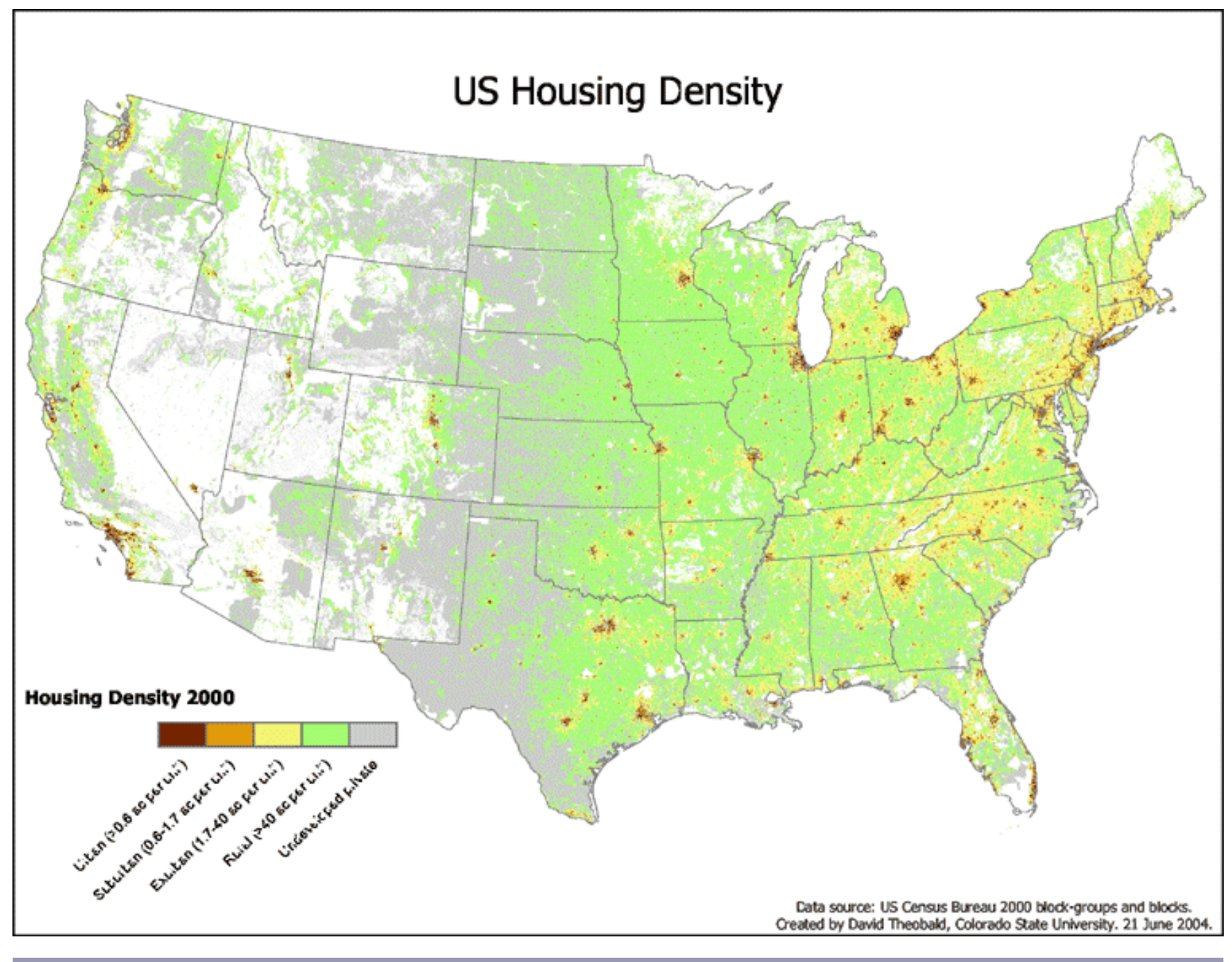

Fig. 8. An animation of national development patterns from 1980 to 2020 .

View animated Figure

Fig. 9. An animation of western U.S. development patterns from 1980 to 2020.
Fig. 10. An animation of central U.S. development patterns from 1980 to 2020.

View animated Figure

Fig. 11. An animation of eastern U.S. development patterns from 1980 to 2020. 
Fig. 12. A map showing the proportion of a county in rural housing density for 1980 .

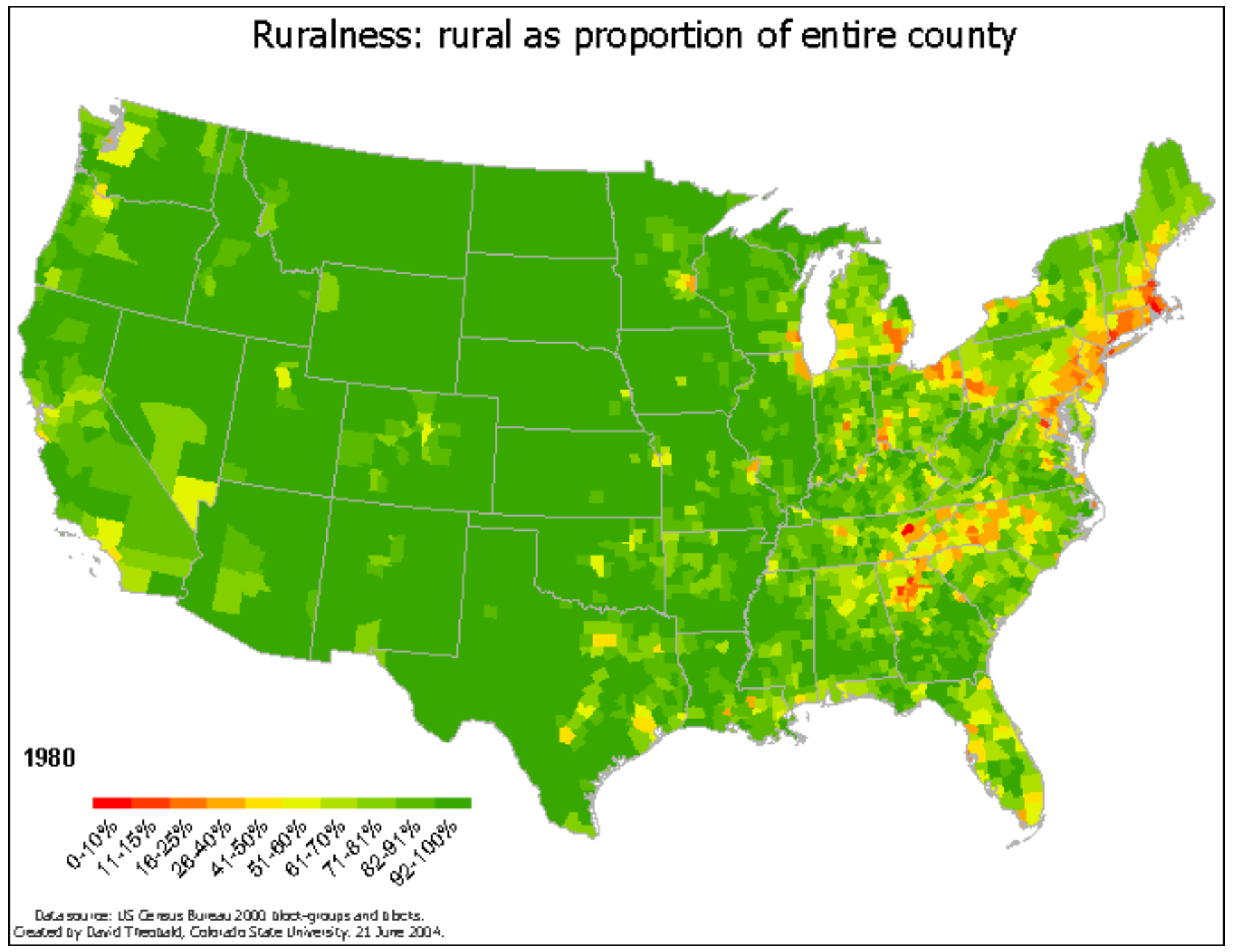

The housing density database produced in this study is intended to complement other existing land-use/ land-cover databases. Compared with the NRI (NRCS 2001) database, it provides a detailed coverage (based on a census, not a sample) that allows spatially explicit patterns to be examined for potential fragmentation effects. Compared with the U.S. Geological Survey/Environmental Protection Agency NLCD (Vogelmann et al. 2001), it provides insight beyond urban and built-up areas into exurban areas. However, as noted earlier, intense urban land uses, such as commercial and industrial, are not captured well in the census data used here, but are readily identified in the NLCD data. Future work will attempt to integrate these two data sets to a greater degree.

The $L S$ metric quantified patterns and locations of urban and exurban sprawl, but requires careful interpretation. Because $L S$ should be summarized by some analytical unit (e.g., a watershed, a county, an MSA), comparisons between different regions must be normalized. $L S$ exhibits a non-linear response to different development patterns that are controlled by two critical parameters. First, at the critical threshold specified by the assumption of the 
Fig. 13. A map showing the proportion of a county in rural housing density for 2000 .

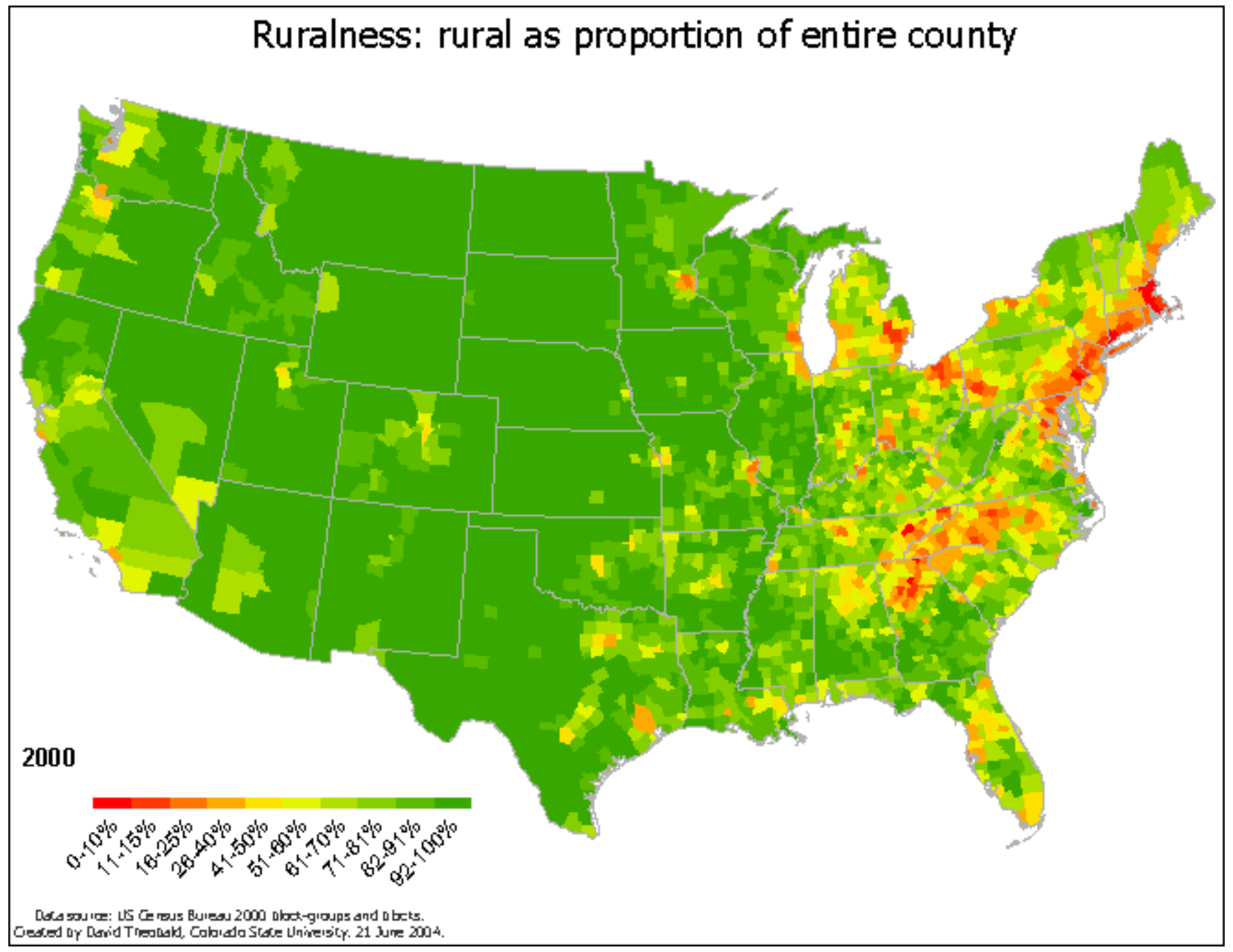

size and contiguity of an urban core, $L S$ adjusts to the emergence of a new urban core area. A onceexurban or rural area that results in large $L S$ values because of long distances to the nearest urban core can rapidly have much reduced $L S$ values as a new urban core emerges. Second, as a rural area is developed and converted to exurban or possibly urban/suburban land use, natural resource or ecological values rapidly diminish. This critical threshold exists roughly at the low-density end of the exurban housing density class. In particular, development edge is defined to occur at the interface between exurban and rural and protected lands, but not at the urban/suburban interface with exurban lands. Of course there are a variety of micro- or sitescale conditions (siting of buildings, landscaping, fencing, allowed or prohibited human activities, etc.) that can also have a strong influence on potential ecological effects that are not accounted for in $L S$. Although these non-linearities and phase changes are more difficult to interpret, this mirrors real-world phenomena that are intrinsic to land-use dynamics (Batty 1997). To progress beyond simple measures of sprawl based on population density changes, these situations need to be explicitly measured. 
Fig. 14. Proportion of a county in rural housing density for 2020.

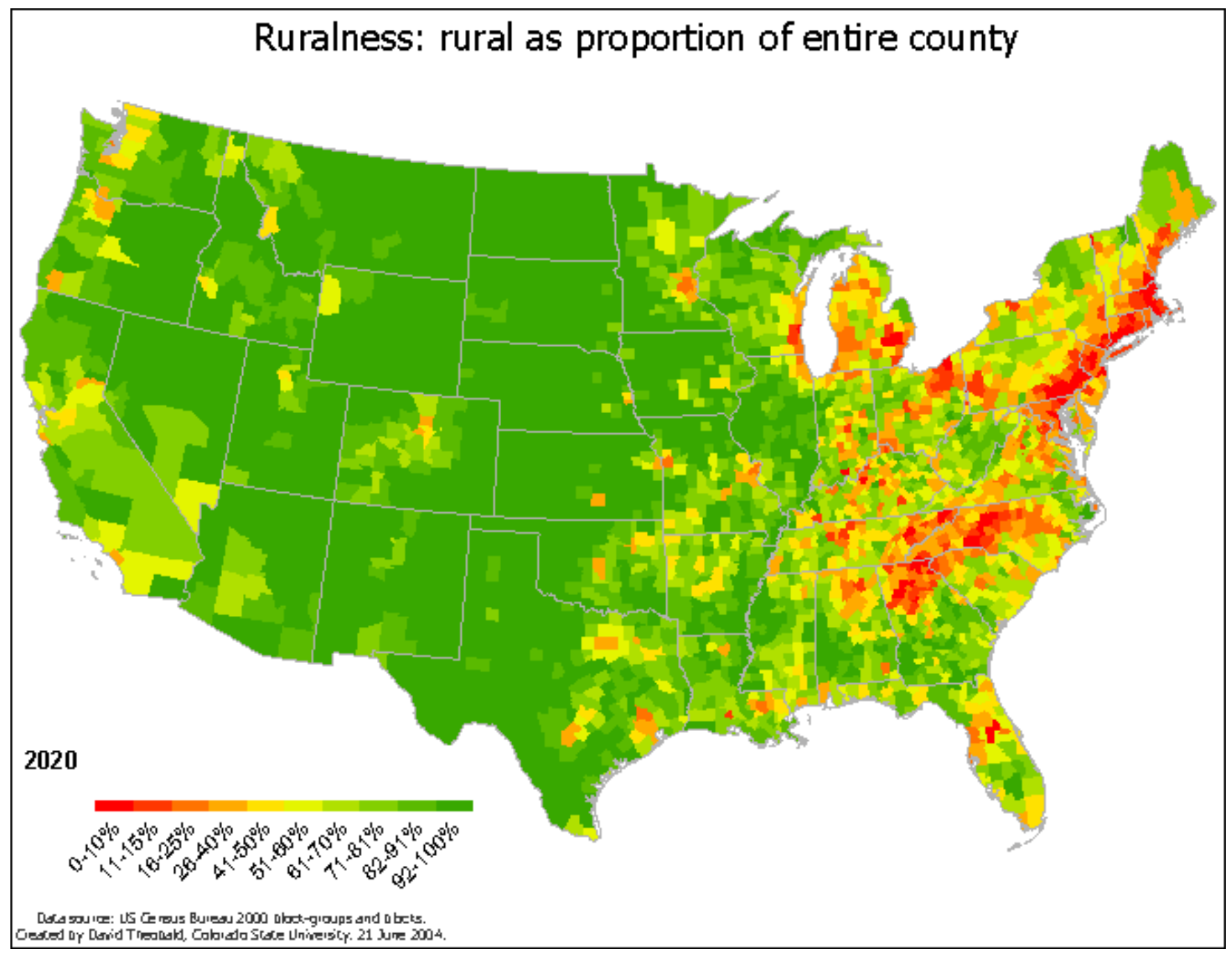

An important challenge for ecologists is to contribute to better understanding of these critical thresholds, their regional variation, and the potential for micro- or site-level measures to mitigate possible broader-scale effects. In general, an initial analysis of development patterns using $L S$ suggests that development patterns that were more contiguous, higher density, and more compact (not dispersed) had reduced overall effects on natural resources because they resulted in smaller footprints or "disturbance zones," lower percentage of impervious surface, and reduced pollution because fewer vehicle miles were generated. Moreover, the practical complications of natural resource management are much reduced with more compact patterns of development. $L S$ is a preliminary metric to quantify the general effects (or impacts) of development patterns on ecological systems. Much work remains to develop causal relationships and more conclusive results, but quantifying development patterns in a logical and consistent manner is an important first step. To complement current work that seeks to understand the ecological consequences of urban sprawl (e.g., Blair 2004), the $L S$ metric needs to be tested by empirical, field- 
Table 2. The results of the test of the SERGoM model comparing estimated areas for urban/suburban, exurban, and rural housing density classes for 1990 and 2000 against forecasted patterns.

\begin{tabular}{|c|c|c|c|c|c|c|c|}
\hline \multicolumn{8}{|c|}{ Resolution 1 ha, Year 1990} \\
\hline \multicolumn{2}{|l|}{ Hectares } & \multicolumn{2}{|l|}{ Forecasted } & \multicolumn{2}{|l|}{$\%$ correct } & \multicolumn{2}{|c|}{ Forecasted } \\
\hline Estimated & Urban & Exurban & Rural & Estimated & Urban & Exurban & Rural \\
\hline Urban & $10,081,521$ & 703,879 & 58,201 & Urban & $93.0 \%$ & $6.5 \%$ & $0.5 \%$ \\
\hline Exurban & 813,885 & $71,055,499$ & $6,050,269$ & Exurban & $1.0 \%$ & $91.2 \%$ & $7.8 \%$ \\
\hline Rural & 8,205 & $4,723,352$ & $473,180,337$ & Rural & $0.0 \%$ & $1.0 \%$ & $99.0 \%$ \\
\hline \multicolumn{8}{|c|}{ Resolution 1 ha, Year 2000} \\
\hline Hectares & & \multicolumn{2}{|l|}{ Forecasted } & \multicolumn{2}{|l|}{$\%$ correct } & \multicolumn{2}{|l|}{ Forecasted } \\
\hline Estimated & Urban & Exurban & Rural & Estimated & Urban & Exurban & Rural \\
\hline Urban & $10,518,408$ & $1,717,056$ & 260,980 & Urban & $84.2 \%$ & $13.7 \%$ & $2.1 \%$ \\
\hline Exurban & 876,047 & $72,573,279$ & $17,994,389$ & Exurban & $1.0 \%$ & $79.4 \%$ & $19.7 \%$ \\
\hline Rural & 21,392 & $4,209,015$ & $458,504,582$ & Rural & $0.0 \%$ & $0.9 \%$ & $99.1 \%$ \\
\hline \multicolumn{8}{|c|}{ Resolution 4 ha, Year 1990} \\
\hline Hectares & & \multicolumn{2}{|l|}{ Forecasted } & \multicolumn{2}{|l|}{$\%$ correct } & \multicolumn{2}{|c|}{ Forecasted } \\
\hline Estimated & Urban & Exurban & Rural & Estimated & Urban & Exurban & Rural \\
\hline Urban & $11,068,972$ & 785,308 & 49,400 & Urban & $93.0 \%$ & $6.6 \%$ & $0.4 \%$ \\
\hline Exurban & 809,680 & $74,892,988$ & $6,119,500$ & Exurban & $1.0 \%$ & $91.5 \%$ & $7.5 \%$ \\
\hline Rural & 3,504 & $4,833,044$ & $478,906,016$ & Rural & $0.0 \%$ & $1.0 \%$ & $99.0 \%$ \\
\hline \multicolumn{8}{|c|}{ Resolution 4 ha, Year 2000} \\
\hline Hectares & & \multicolumn{2}{|l|}{ Forecasted } & \multicolumn{2}{|l|}{$\%$ correct } & \multicolumn{2}{|l|}{ Forecasted } \\
\hline Estimated & Urban & Exurban & Rural & Estimated & Urban & Exurban & Rural \\
\hline Urban & $11,550,736$ & $1,928,984$ & 243,824 & Urban & $84.2 \%$ & $14.1 \%$ & $1.8 \%$ \\
\hline Exurban & 857,476 & $76,444,180$ & $18,312,696$ & Exurban & $0.9 \%$ & $80.0 \%$ & $19.2 \%$ \\
\hline Rural & 15,352 & $4,318,952$ & $463,796,212$ & Rural & $0.0 \%$ & $0.9 \%$ & $99.1 \%$ \\
\hline
\end{tabular}


Resolution 16 ha, Year 1990

\begin{tabular}{|c|c|c|c|c|c|c|c|}
\hline Hectares & & Forecasted & & $\%$ correct & & Forecaste & \\
\hline Estimated & Urban & Exurban & Rural & Estimated & Urban & Exurban & Rural \\
\hline Urban & $12,110,992$ & 874,304 & 36,560 & Urban & $93.0 \%$ & $6.7 \%$ & $0.3 \%$ \\
\hline Exurban & 829,216 & $80,066,768$ & $6,181,248$ & Exurban & $1.0 \%$ & $91.9 \%$ & $7.1 \%$ \\
\hline Rural & 1,552 & $5,034,896$ & $488,480,752$ & Rural & $0.0 \%$ & $1.0 \%$ & $99.0 \%$ \\
\hline
\end{tabular}

Resolution 16 ha, Year 2000

\begin{tabular}{lrrrrrrr} 
Hectares & \multicolumn{2}{c}{ Forecasted } & \multicolumn{2}{c}{$\%$ correct } & \multicolumn{3}{c}{ Forecasted } \\
\hline Estimated Urban & Exurban & Rural & Estimated & Urban & Exurban & Rural \\
Urban & $12,663,840$ & $2,178,672$ & 203,248 & Urban & $84.2 \%$ & $14.5 \%$ & $1.4 \%$ \\
Exurban & 855,936 & $81,695,040$ & $18,712,096$ & Exurban & $0.8 \%$ & $80.7 \%$ & $18.5 \%$ \\
Rural & 12,304 & $4,487,488$ & $472,807,664$ & Rural & $0.0 \%$ & $0.9 \%$ & $99.1 \%$ \\
\hline
\end{tabular}

Resolution 64 ha, Year 1990

\begin{tabular}{|c|c|c|c|c|c|c|c|}
\hline Hectares & & Forecasted & & $\%$ correct & & Forecaste & \\
\hline Estimated & Urban & Exurban & Rural & Estimated & Urban & Exurban & Rural \\
\hline Urban & $13,213,056$ & 944,640 & 22,144 & Urban & $93.2 \%$ & $6.7 \%$ & $0.2 \%$ \\
\hline Exurban & 941,440 & $87,619,200$ & $6,249,408$ & Exurban & $1.0 \%$ & $92.4 \%$ & $6.6 \%$ \\
\hline Rural & 1,536 & $5,609,664$ & $502,895,232$ & Rural & $0.0 \%$ & $1.1 \%$ & $98.9 \%$ \\
\hline
\end{tabular}

Resolution 64 ha, Year 2000

\begin{tabular}{|c|c|c|c|c|c|c|c|}
\hline Hectares & & Forecasted & & $\%$ correct & & Forecaste & \\
\hline Estimated & Urban & Exurban & Rural & Estimated & Urban & Exurban & Rural \\
\hline Urban & $13,864,576$ & $2,466,880$ & 145,536 & Urban & $84.1 \%$ & $15.0 \%$ & $0.9 \%$ \\
\hline Exurban & 943,488 & $89,389,248$ & $19,349,632$ & Exurban & $0.9 \%$ & $81.5 \%$ & $17.6 \%$ \\
\hline Rural & 10,944 & $4,985,664$ & $486,340,352$ & Rural & $0.0 \%$ & $1.0 \%$ & $99.0 \%$ \\
\hline
\end{tabular}

Resolution 256 ha, Year 1990

\begin{tabular}{|c|c|c|c|c|c|c|c|c|}
\hline Hectares & & Forecasted & & & $\%$ correct & & Forecast & \\
\hline Estimated & Urban & Exurban & Rural & & Estimated & Urban & Exurban & Rural \\
\hline Urban & $14,220,288$ & 990,976 & & 9,728 & Urban & $93.4 \%$ & $6.5 \%$ & $0.1 \%$ \\
\hline
\end{tabular}




\begin{tabular}{lrrrrrr}
\hline Exurban & $1,122,560$ & $99,425,792$ & $6,576,896$ Exurban & $1.0 \%$ & $92.8 \%$ & $6.1 \%$ \\
Rural & 1,792 & $6,311,424$ & $520,506,624$ Rural & $0.0 \%$ & $1.2 \%$ & $98.8 \%$ \\
\hline
\end{tabular}

Resolution 256 ha, Year 2000

\begin{tabular}{|c|c|c|c|c|c|c|c|}
\hline Hectares & & Forecasted & & $\%$ correct & & Forecaste & \\
\hline Estimated & Urban & Exurban & Rural & Estimated & Urban & Exurban & Rural \\
\hline Urban & $15,015,680$ & $2,697,728$ & 83,712 & Urban & $84.4 \%$ & $15.2 \%$ & $0.5 \%$ \\
\hline Exurban & $1,119,744$ & $101,425,408$ & $20,720,384$ & Exurban & $0.9 \%$ & $82.3 \%$ & $16.8 \%$ \\
\hline Rural & 10,752 & $5,472,512$ & $502,620,160$ & Rural & $0.0 \%$ & $1.1 \%$ & $98.9 \%$ \\
\hline
\end{tabular}

based research as well.

Because quantification of development patterns in general and $L S$ in particular are sensitive to the finegrained pattern of protected lands, additional effort is needed to create better and more complete databases of protected lands. For example, over 9.4 million acres of land in the U.S. was protected by local and regional land trusts in 2003, a $494 \%$ increase over the 1.9 million acres in 1990 (Land Trust Alliance 2004). The vast majority of these lands were not mapped in the Protected Areas Database (PAD) data set used in this study (DellaSala et al. 2001). Moreover, forecast models of land use need to incorporate possible feedbacks of development that locate growth in response to protected lands.

\section{Speculation}

A number of additional uses of the housing density data set are foreseen and underway, such as summarizing the housing densities by watershed to examine the potential effects of development on water quality, and a standard way to map the wildland-urban interface and intermix (WUI). A novel way to assess the dynamics of land-use change at the WUI is through a resilience perspective. Resilience is defined as the amount of change a system can experience before it is forced to reorganize (Peterson 2002). In the context of development patterns, patterns of development can be viewed as the state resulting from processes (largely socio-economic, but some ecological) that structure the landscape at the urban/exurban fringe. Resilience could then measure the amount or degree of control on processes at this interface, providing a way to examine the fundamental tension at the interface zone. Cross-scale edge has been developed to quantify resilience to identify the ecotone of instability, which is commonly identified using percolation theory that identifies thresholds between 0.407 to 0.593 , computed at multiple scales (Peterson 2002). As a preliminary query of using the housing density database, I reclassified housing density into urban/suburban/exurban vs. rural/ protected categories and computed cross-scale edge, by calculating the proportion of times a cell is identified as edge (using 0.2, 0.4, 0.6, 0.8, 1.6, and $2.4 \mathrm{~km}$ radius; Fig. 18). This method appears to identify the relative instability of the interface, which might provide an alternative way in which to understand how development patterns may constrain or modify ecological processes at a range of scales.

\section{CONCLUSION}

I have argued that it is critical for ecologists to examine and improve understanding of land-use changes beyond the urban fringe to examine the extent, trend, and pattern of "exurban sprawl." Extensive and widespread land-use changes have occurred and are likely to continue. Based on the nationwide, fine-grained database of historical, current, and forecasted housing density, there were slightly over seven times the additional area $(917$ $\left.090 \mathrm{~km}^{2}\right)$ in exurban housing density $(0.68-16.18$ ha per unit) compared with $125729 \mathrm{~km}^{2}$ in urban/ suburban $(<0.68$ ha per unit). The developed footprint has grown from $10.1 \%$ to $13.3 \%$ (1980 to $2000)$, roughly at a rate of $1.60 \%$ per year. This rate 
Fig. 15. Landscape sprawl metric values for the U.S. in 2000, averaged by county. Higher values indicate more sprawl or greater effect on the landscape.

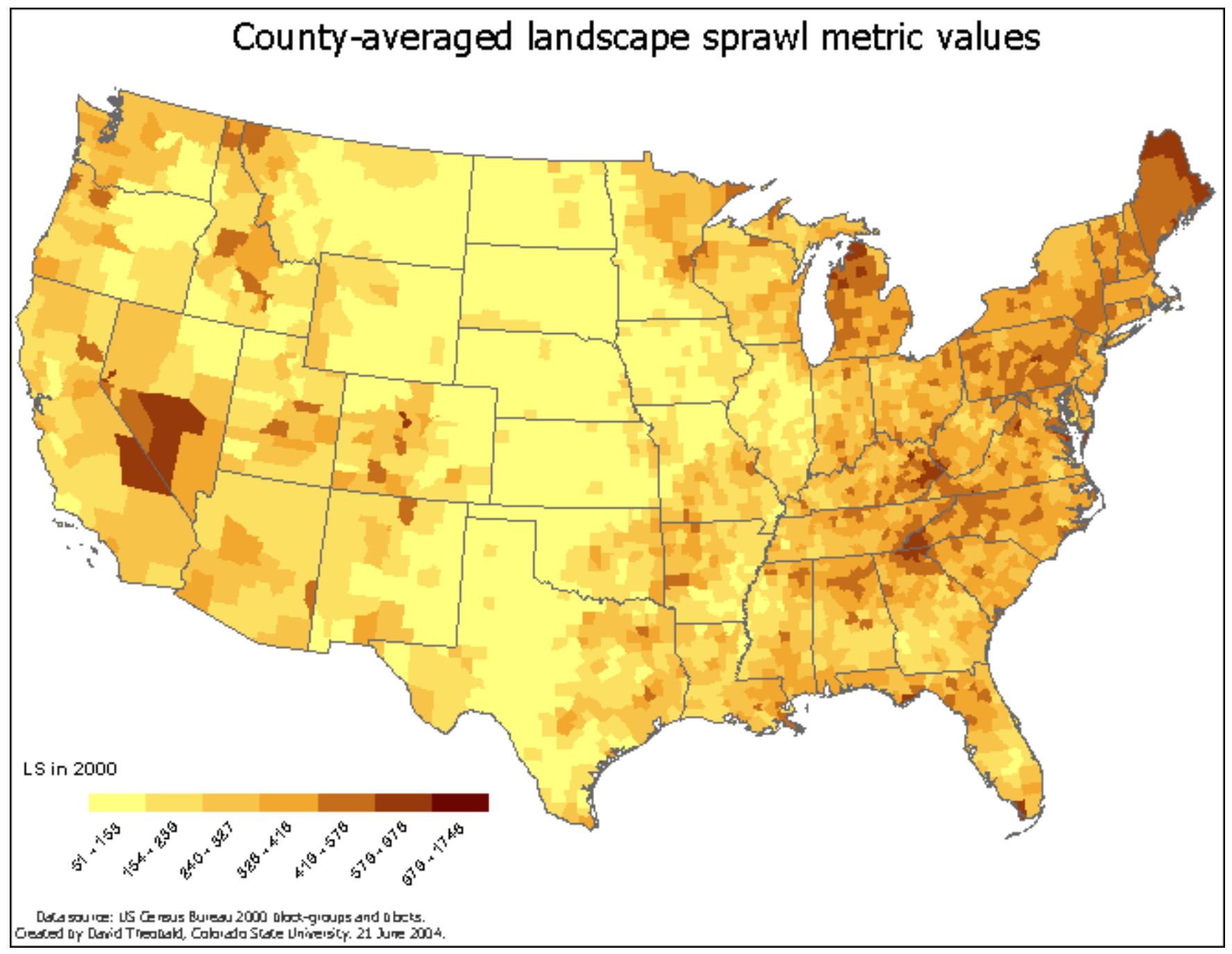

of land development outpaced by $25 \%$ the population growth rate $(1.18 \%$ per year). The SERGoM forecast model resulted in overall reasonable accuracies (using hindcasts to 1990 and 2000 from 1980) ranging from $79.4 \%$ to $91.2 \%$ for exurban densities. Based on these forecasts, urban/ suburban housing densities will expand to $2.2 \%$ by 2020, whereas exurban will expand to $14.3 . \%$

Numerous possible applications of the housing density database are possible, particularly those that examine the implications of process-level understanding. The landscape sprawl metric is one example, allowing current understanding of the factors that generate undesirable land-use patterns (sprawl) to be explicitly represented and examined in a consistent, national framework.

Values of the landscape sprawl metric indicated a general nationwide trend of urban and exurban sprawl. $L S$ values increased from 232 to 248 to 263 (from 1980 to 2000 to 2020). Other investigations of broad-scale ecological issues, such as the wildland-urban interface, nature reserve design, 
Fig. 16. A detailed map of the Landscape Sprawl (LS) metric values for northern Colorado, USA in 2000. Higher values (red) indicate more sprawl or greater effect on the landscape. Private rural lands with no housing density are shown by gray, and public/protected lands are shown in white. Note that the LS metric is evaluated for all areas, and exurban/rural sprawl can be seen to extend beyond the boundaries of the 2000 Census Urban Areas (black outline).

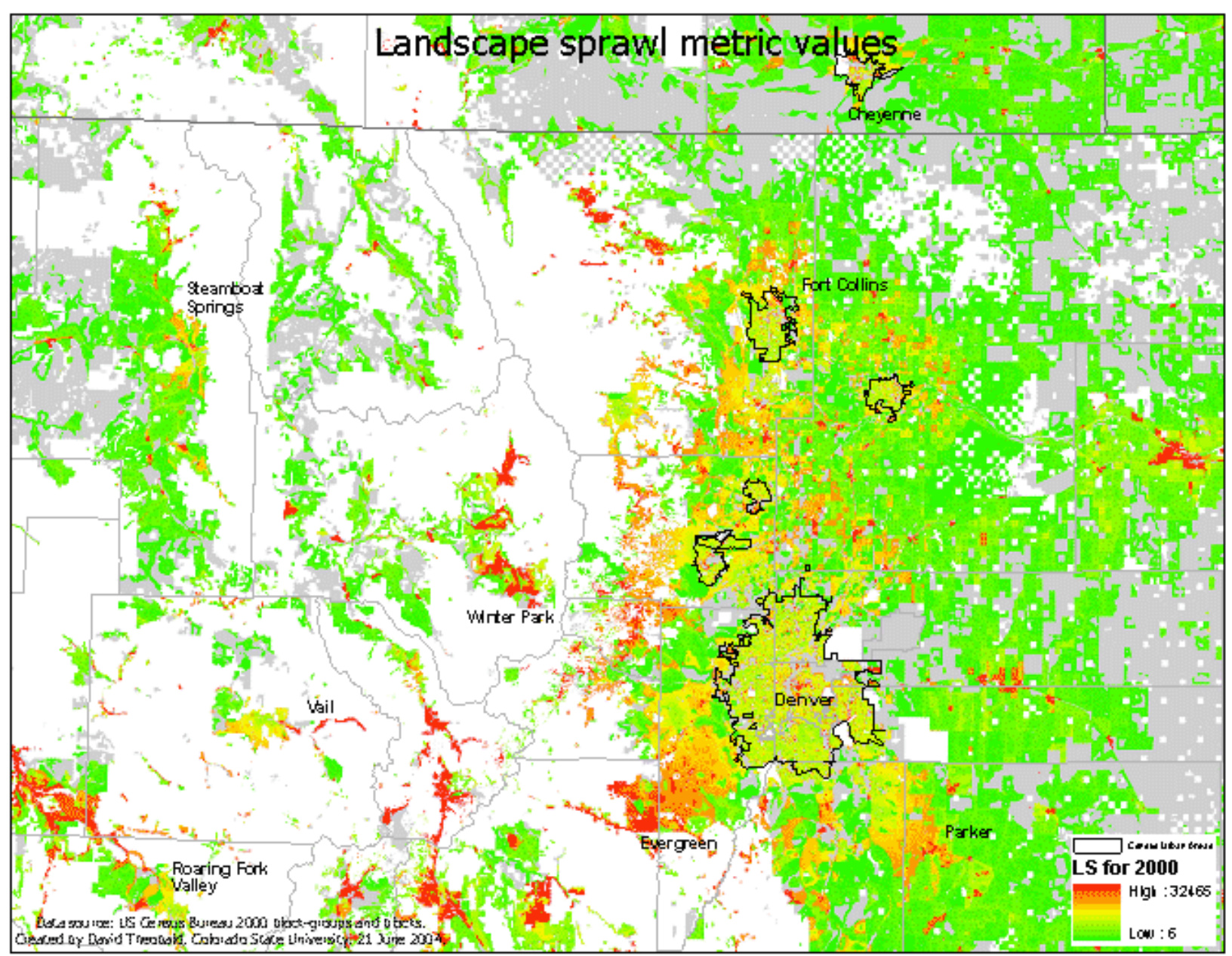


Fig. 17. An animation of the Landscape Sprawl (LS) metric values for northern Colorado, USA for 1980, 2000, and 2020. Higher values (red) indicate more sprawl or greater effect on the landscape. Private rural lands with no housing density are shown in gray, and public/protected lands are shown in white. Note that the LS metric is evaluated for all areas, and rural sprawl can be seen to extend beyond the boundaries of the 2000 Census Urban Areas (black outline). Development can be seen to expand into outlying areas at a more rapid pace than the housing density maps depict. For example, the region to the south and southeast of Denver (near the City of Parker and Douglas County) can be seen to expand rapidly from 1980 to 2000 , and is forecast to expand yet again by 2020. Because a key component of the LS metric is distance from urban core, and urban core areas emerge over time, there are some significant phase changes or discontinuities in the LS values. For example, in the region around Evergreen located southwest of Denver, LS values increase rapidly from 1980 to 2000. By 2020, apparently enough land has been converted to urban density that a new urban core area will be established. This complex phase transition is a powerful, but as yet not well understood aspect of exurban land dynamics.

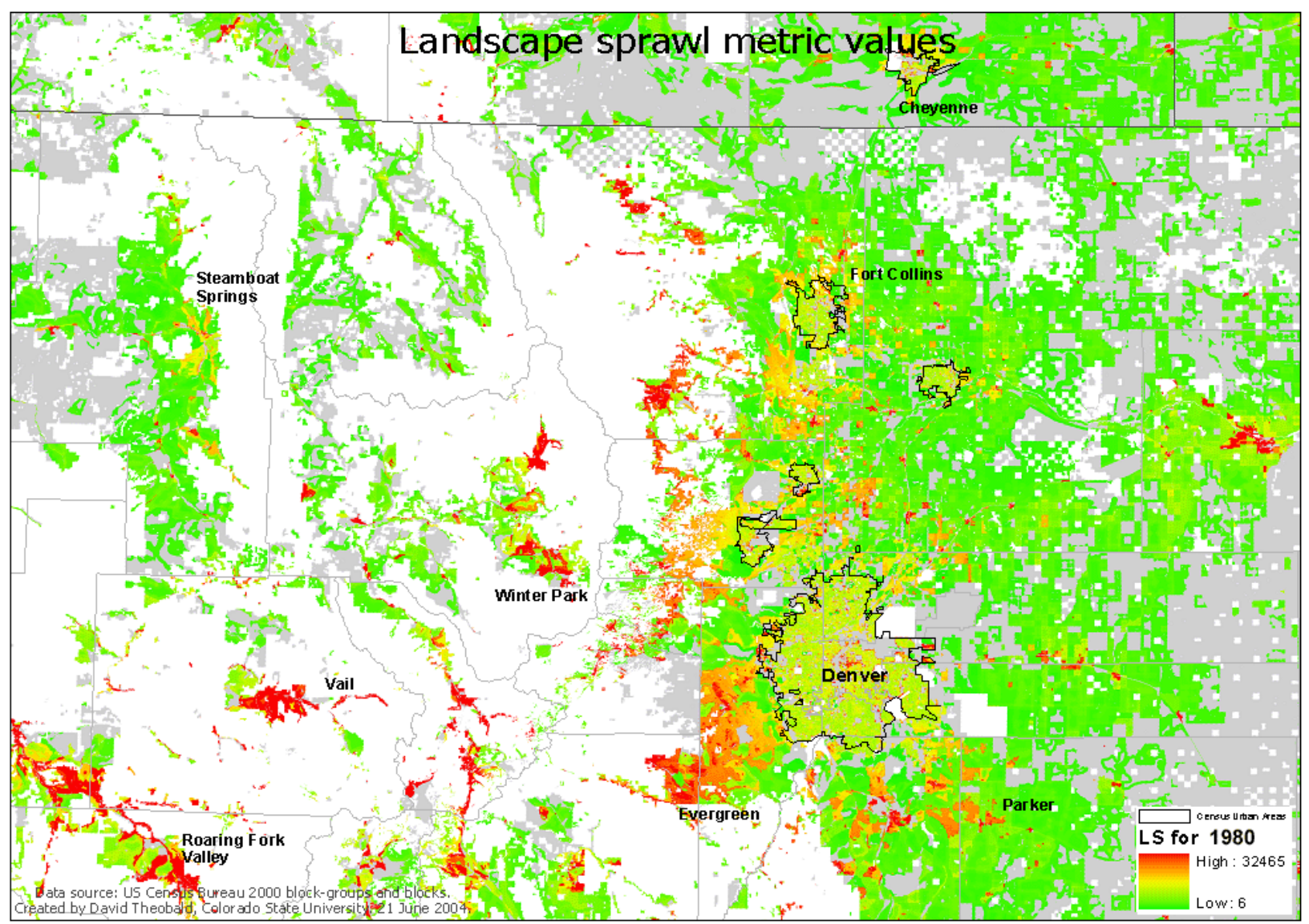


Fig. 18. An exploration of the application of the concept of landscape resilience to identifying the dynamic fringe of exurban development. Cross-scale edge was computed on a portion of landscape around Fort Collins, Colorado, USA using developed/undeveloped patterns at six scales (using 0.2, 0.4, 0.6, 0.8, 1.6, and $2.4 \mathrm{~km}$ radius). Locations in red depict high probability of instability, orange moderate instability, and yellow low instability (green is stable, lakes are shown in blue, gray lines show major roads).

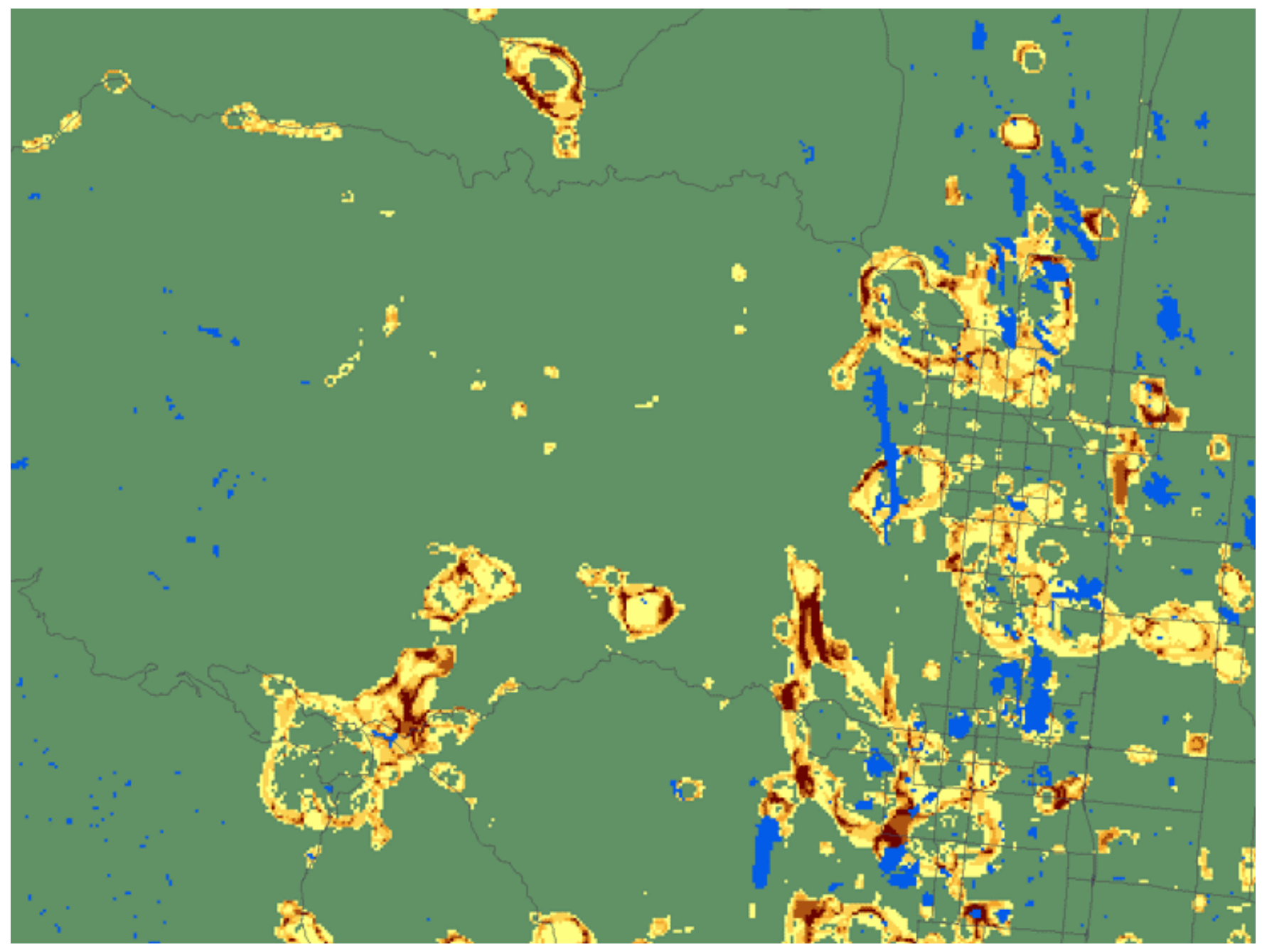

and air quality sources and effects, may find utility in this database.

\section{Acknowledgments:}

Responses to this article can be read online at: http://www.ecologyandsociety.org/vollo/iss 1/art32/responses/

This research was supported in part by a grant from the USDA National Research Initiative (Award No. 2003-35401-13801, NRI, CSREES, USDA). 


\section{LITERATURE CITED}

Alberti, M. 1999. Urban patterns and environmental performance: what do we know? Journal of Planning Education and Research 19:151-163.

Alig, R. J., and R. G. Healy. 1987. Urban and builtup land area changes in the United States: an empirical investigation of determinants. Land Economics 63:215-226.

Alonso, W. 1993. The interpenetration of rural and urban America. Pages 23-28 in L. L. Swanson and D. L. Brown, editors. Population change and the future of rural America. Agriculture and Rural Economy Division, Economic Research Service, U. S. Department of Agriculture. Report No. AGES 9324.

Bank of America. 1996. Beyond sprawl: new patterns of growth to fit the new California. [Online.] URL:

http://www.rut.com/misc/beyondSprawl.html.

Batty, M. 1997. Cellular automata and urban form: a primer. Journal of the American Planning Association 63(2):266-274.

Benfield, F. K., M. D. Raimi, and D. D. Chen. 1999. Once there were greenfields: how urban sprawl is undermining America's environment, economy, and social fabric. National Resources Defense Council, Washington, D.C., U.S.A.

Blair, R. 2004. The effects of urban sprawl on birds at multiple levels of biological organization. Ecology and Society 9(5):2. [Online.] URL:

http://www.ecologyandsociety.org/vol9/iss5/art2.

Carrion-Flores, C., and E. G. Irwin. 2004. Determinants of residential land-use conversion and sprawl at the rural-urban fringe. American Journal of Agricultural Economics 86(4):889-904.

Claggett, P. R., C. A. Jantz, S. J. Goetz, and C. Bisland. 2004. Assessing development pressure in the Chesapeake Bay watershed: an evaluation of two land-use change models. Environmental Monitoring and Assessment 94:129-146.

Clarke, K. 1997. Long term urban growth prediction using a cellular automaton model and GIS: applications in San Francisco and Washington/ Baltimore. Paper presented at the International
Workshop on GIS in Spatial Population Analysis and Regional Economic Development, 24-25 March 1997, Hong Kong.

Costanza, R. 1989. Model goodness of fit: a multiple resolution procedure. Ecological Modelling 47:199-215.

Daniels, T. 1999. What to do about rural sprawl? [Online.] URL:

http://www.mrsc.org/subjects/planning/rural/daniels. aspx.

DellaSala, D. A., N. L. Staus, J. R. Strittholt, A. Hackman, and A. Iacobelli. 2001. An updated protected areas database for the United States and Canada. Natural Areas Journal 21:124-135.

Eicher, C. L. and C. A. Brewer. 2001. Dasymetric mapping and areal interpolation: implementation and evaluation. Cartography and Geographic Information Science 28:125-138.

El Nasser, H., and P. Overberg. 2001. A comprehensive look at sprawl in America. U.S.A Today February 22. [Online.] URL:

http://www.usatoday.com/news/sprawl/main.htm.

Ewing, R. 1994. Characteristics, causes, and effects of sprawl: a literature review. Environmental and Urban Issues 21(2):1-15.

Ewing, R. 1997. Is Los Angeles-style sprawl desirable? Journal of American Planning Association (Winter):107-126.

Ewing, R., J. Kostyack, D. Chen, B. Stein, and M. Ernst. 2005. Endangered by sprawl: how runaway development threatens America's wildlife. National Wildlife Federation, Smart Growth America, and NatureServe. Washington, D.C., U.S. A.

Ewing, R., R. Pendall, and D. Chen. 2002. Measuring sprawl and its impact. [Online.] URL: www.smartgrowthamerica.com.

Firestone, D. 2001. 90's suburbs of west and south: denser in one, sprawling in other. New York Times. April $17^{\text {th }}$. [Online.] URL:

http://www.sprawlcity.org/news/01-0417.html.

Galster, G., R. Hanson, H. Wolman, and S. Coleman. 2000. Wrestling sprawl to the ground: 
defining and measuring an elusive concept. Report for Fannie Mae Foundation, Washington, D.C., USA.

Hammer, R. B., S. I. Stewart, R. L. Winkler, V. C. Radeloff, and P. R. Voss. 2004. Characterizing dynamic spatial and temporal residential density patterns from 1940-1990 across the north central United States. Landscape and Urban Planning 69:183-199.

Hart, J. F. 1992. Nonfarm farms. Geographical Review 82(2):166-179.

Hasse, J. E., and R. G. Lathrop. 2003. Land resource impact indicators of urban sprawl. Applied Geography 23:159-175.

Holloway, S. R., J. V. Schumacher, and R. L. Redmond. 1999. People and place: dasymetric mapping using ARC/INFO. Pages 283-291 in S. Morain, editor. GIS solutions in natural resource management: balancing the technical-political equation. OnWord Press, Santa Fe, New Mexico.

Katz, B., and A. Liu. 2000. Moving beyond sprawl: toward a broader metropolitan agenda. The Brookings Review 18(2):31-34.

Kolankiewicz, L., and R. Beck. 2001. Weighing sprawl factors in large U.S. cities: analysis of U.S. Bureau of the Census data on the 100 largest urbanized areas of the United States. March 19. [Online.] URL:

http://www.sprawlcity.org/index.html.

Land Trust Alliance. 2004. National land trust census. [Online.] URL:http://www.lta.org/census.

Landis, J. D. 1995. Imagining land use futures: applying the California urban futures model. Journal of the American Planning Association 61:438-457.

Lang, R. E. 2003. Open spaces, bounded places: does the American West's arid landscape yield dense metropolitan growth? Housing Policy Debate 13(4):755-778.

Longley, P. A., M. F. Goodchild, D. J. Maguire, and D. W. Rhind. 2001. Geographic information systems and science. John Wiley, West Sussex, UK.

Luck, M., and J. G. Wu. 2002. A gradient analysis of urban landscape pattern: a case study from the Phoenix metropolitan region, Arizona, U.S.A. Landscape Ecology 17(4):327-339.

McGarigal, K., and B .J. Marks. 1995. FRAGSTATS: spatial pattern analysis program for quantifying landscape structure. U.S.DA Forest Service, Pacific Northwest Research Station, Portland, Oregon, U.S.A. General Technical Report PNW-GTR-351.

Monmonier, M., and G. A. Schnell. 1984. Land use and land cover data and the mapping of population density. International Yearbook of Cartography 24:24-29.

Natural Resources Conservation Service (NRCS). 2001. National resource inventory. U.S. Department of Agriculture, Washington, D.C., USA.

NPA Data Services. 2003. County population projections-key indicators of county growth, 1970-2024, extended to 2030. NPA Data Services, Arlington, Virginia, U.S.A.

Openshaw, S. 1984. The modifiable areal unit problem. Concepts and Techniques in Modern Geography Series, Vol. 38. GeoBooks, Norwich, UK.

Pendall, R. 1999. Do land-use controls cause sprawl? Environment and Planning B-Planning \& Design 26(4):555-571.

Peterson, G. D. 2002. Estimating resilience across landscapes. Conservation Ecology 6(1):17. (Online.) URL:

http://www.ecologyandsociety.org/vol6/iss1/art17

Pontius, R. G. Jr. 2002. Statistical methods to partition effects of quantity and location during comparison of categorical maps at multiple resolutions. Photogrammetric Engineering \& Remote Sensing 68(10):1041-1049.

Radeloff, V. C., R. B. Hammer, P. R. Voss, A. E. Hagen, D. R. Field, and D. J. Mladenoff. 2001. Human demographic trends and landscape level forest management in the northwest Wisconsin Pine Barrens. Forest Science 47 (2):229-241.

Ricketts, T. and M. Imhoff. 2003. Biodiversity, urban areas, and agriculture: locating priority 
ecoregions for conservation. Conservation Ecology 8(2):1. [Online.] URL:

http://www.consecol.org/vol8/iss2/art1.

Robinson, A. H., J. L. Morrison, P. C. Muehrcke, and S. C. Guptill. 1995. Elements of cartography. John Wiley, New York, New York, U.S.A.

Robinson, L., J. P. Newell, and J. M. Marzluff. 2005. Twenty-five years of sprawl in the Seattle region: growth management responses and implications for conservation. Landscape and Urban Planning 71:51-72.

Rusk, D. 1997. Debate on theories of David Rusk. The Regionalist, Fall 1997.

Schumacher, J. V., R. L. Redmond, M. M. Hart, and M. E. Jensen. 2000. Mapping patterns of human use and potential resource conflicts on public lands. Environmental Monitoring and Assessment 64:127-137.

Sierra Club. 1998. The dark side of the American dream: the costs and consequences of suburban sprawl. [Online.] URL:

http://www.sierraclub.org/sprawl/report98/.

Song, Y., and G. J. Knaap. 2004. Measuring urban form: is Portland winning the war on sprawl? Journal of the American Planning Association 70 (2):210-225.

Theobald, D. M. 2000. Fragmentation by inholdings and exurban development. Pages 155174 in R. L. Knight, F. W. Smith, S. W. Buskirk, W. H. Romme, and W. L. Baker, editors. Forest fragmentation in the southern Rocky Mountains. University Press of Colorado, Boulder, Colorado, U.S.A .

Theobald,D.M. 2001a. Land use dynamics beyond the American urban fringe. Geographical Review 91:544-564.

Theobald, D. M. 2001b. Technical description of mapping historical, current, and future housing densities in the U.S. using Census block-groups. Natural Resource Ecology Lab, Colorado State University, Fort Collins, Colorado, U.S.A.

Theobald, D. M. 2003. Targeting conservation action through assessment of protection and exurban threats. Conservation Biology 17:1624-
1637.

Theobald, D. M. 2004. Placing exurban land use change in a human modification framework. Frontiers in Ecology and Environment 2(3):139144.

Theobald, D. M., H. Gosnell, and W. E. Riebsame. 1996. Land use and landscape change in the Colorado Mountains, II: a case study of the East River valley. Mountain Research and Development 16(4):407-418.

Theobald, D. M., and N. T. Hobbs. 1998. Forecasting rural land use change: a comparison of regression- and spatial transition-based models. Geographical \& Environmental Modelling 2:6582.

Theobald, D. M., J. M. Miller and N. T. Hobbs. 1997. Estimating the cumulative effects of development on wildlife habitat. Landscape and Urban Planning 39(1):25-36.

Torrens, P. M. and M. Alberti. 2000. Measuring sprawl. CASA Working Paper 27. Centre for Advanced Spatial Analysis, University College, London, UK. [Online.] URL:

http://www.casa.ucl.ac.uk/measuring sprawl.pdf.

U.S. Census Bureau. 2001a. Census 2000 Summary File 1 Technical Documentation. U.S. Census Bureau, Washington, D.C., U.S.A.

U.S. Census Bureau. 2001b. Census 2000 Summary File 1. U.S. Census Bureau, Washington, D.C., U.S.A.

U.S. Census Bureau. 2001c. Census 2000 Summary File 3. U.S. Census Bureau, Washington, D.C., U.S.A.

U.S. Department of Transportation. 2003. NHTS 2001 Highlights Report. Bureau of Transportation Statistics, report BTS03-05, Washington, D.C., U. S.A.

Vogelmann, J. E., S. M. Howard, L. Yang, C. R. Larson, B. K. Wylie, and N. van Driel. 2001. Completion of the 1990s National Land Cover Data Set for the conterminous United States from Landsat Thematic Mapper data and ancillary data sources. Photogrammetric Engineering and Remote Sensing 67:650-652. 
Waldie,D.J.2000. Do the voters really hate sprawl? New York Times 3 March 2000.

Ward, D., S. R. Phinn, and A. T. Murray. 2000. Monitoring growth in rapidly urbanizing areas using remotely sensed data. Professional Geographer 52 (3):371-386.

Wilson, E. H., J. D. Hurd, D. L. Civco, M. P. Prisloe, and C. Arnold. 2003. Development of a geospatial model to quantify, describe and map urban growth. Remote Sensing of Environment $86: 275-385$.

Wright, J. K. 1936. A method of mapping densities of population. Geographical Review 26:103-110. 
APPENDIX 1. The program to compute the Landscape Sprawl metric, written in ArcINFO Arc Macro Language

\&echo \&on

\&args $r$ y

\&watch combine_[date -tag].watch

\&ty [date -full]

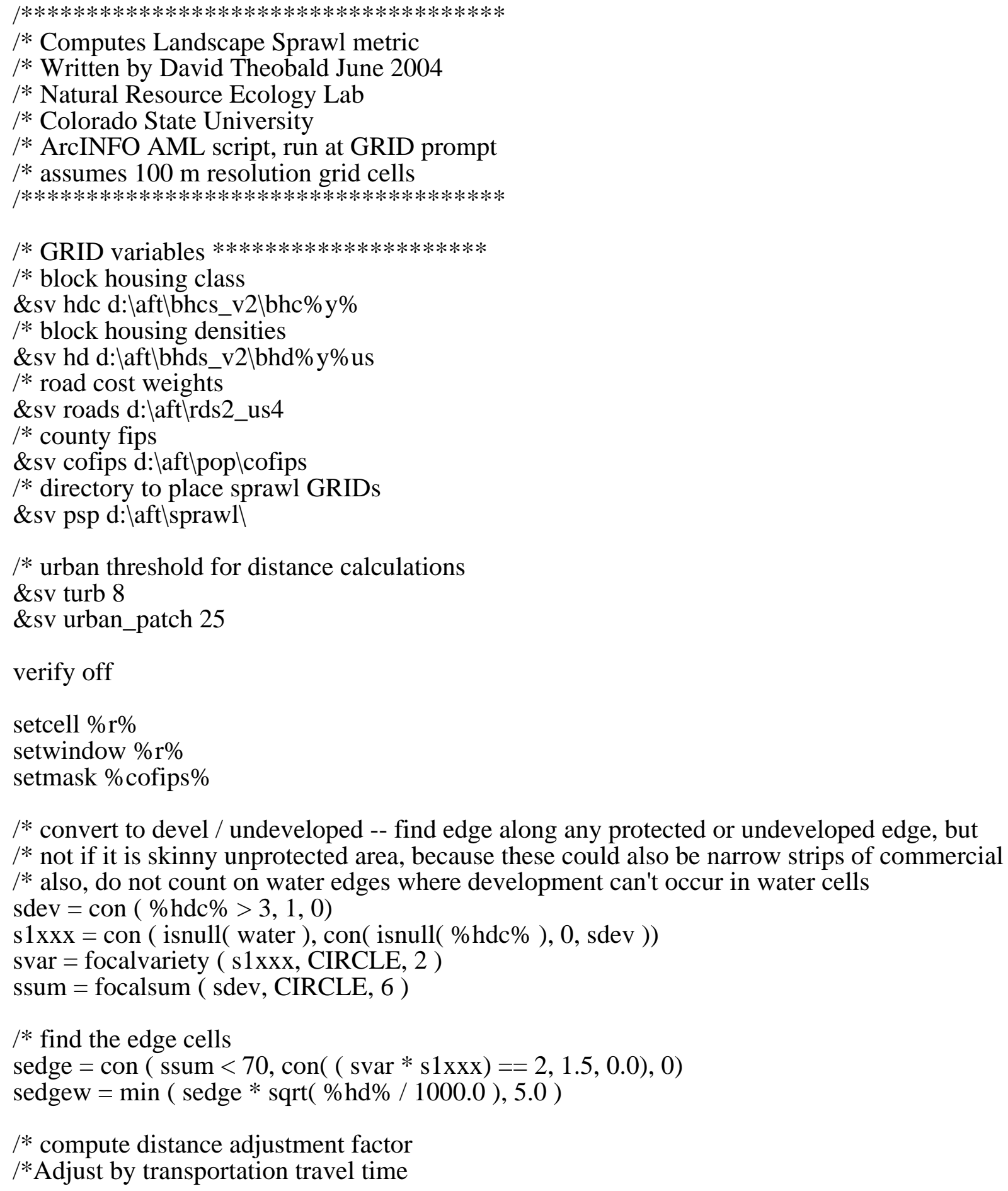


setcell \%roads $\%$

setmask \%cofips\%

GU4xx1 = con $(\%$ hdc $\%>=\%$ turb $\%, 1)$

/* filter urban areas to remove small ones <

GU4xxx1 = regiongroup $(\mathrm{GU} 4 \times \mathrm{X} 1)$

buildvat GU4XXx1

/* transform distance in minutes traveled so that 60 minutes travel is twice

GU4x = expand ( con (GU4XXX1.COUNT > \%urban_patch\%, 1 ), 1, LIST, 1)

GD4U $=$ COSTDISTANCE ( GU4x, \%roads $\%) / 100000$

GD4UT $=\max ($ POW $($ GD4U, 0.5$), 1.0)$

\&ty [date -full]

setcell $\% \mathrm{r} \%$

sacc $=$ gd4ut $* \operatorname{sqrt}(\%$ hd $\% / 1000.0)$

/* compute efficiency in housing units on landscape

seff1 $=\operatorname{sqrt}(1.0 /(\%$ hd $\% / 1000.0))$

seff $=$ con $($ seff $1<=4.02$, seff 1 , con $(\operatorname{seff} 1<=4.49$, seff $1 * 0.6$, con $(\operatorname{seff} 1<=5.68$, seff $1 * 0.1$, seff $1 *$ $0.001)))$

/* compute ls, need to not compute housing density on agricultural areas...

$\%$ psp $\% 1$ s $\%$ y\%\%r\% $=$ int $(($ sedgew + seff + sacc $) * 100)$

\&ty [date -full]

\&echo \&off 
Appendix 2. A high resolution map of US Housing Density for 2000 ( 4.7MB).

\section{Please click here to download file 'appendix2.pdf'.}


Appendix 3. Summaries of development patterns by county for 1980, 2000, and 2020 in MS Excel format. 
Appendix 4. Summaries of Landscape Sprawl metric values by county for 1980, 2000, and 2020 in MS Excel format. 